\title{
THE CONTROL OF FIRING PATTERN IN NIGRAL DOPAMINE NEURONS: BURST FIRING ${ }^{1}$
}

\author{
ANTHONY A. GRACE ${ }^{2}$ AND BENJAMIN S. BUNNEY ${ }^{3}$ \\ Departments of Psychiatry and Pharmacology, Yale University School of Medicine, New Haven, Connecticut 06510
}

Received February 14, 1984; Revised May 14, 1984; Accepted June 6, 1984

\begin{abstract}
In addition to firing in a single spiking mode, dopamine (DA) cells have been observed to fire in a bursting pattern with consecutive spikes in a burst displaying progressively decreasing amplitude and increasing duration. In vivo intracellular recording demonstrated the bursts to typically ride on a depolarizing wave (5 to $15 \mathrm{mV}$ amplitude). Although the burst-firing frequency of DA cells showed little correlation with the base line firing rate, increases in firing rate were usually associated with an increase in burst firing. Increases in burst firing could also be elicited by intracellular calcium injection and could be prevented by intracellular injection of EGTA, suggesting a calcium involvement in bursting. Blockade of potassium conductances with extracellular iontophoresis of barium or intracellular injection of tetraethylammonium bromide could also trigger an increased degree of burst firing in DA cells. These data suggest that the increased calcium influx accompanying an increased firing rate triggers burst firing, possibly by inactivating a potassium conductance. A switch from a single spiking mode to a burst-firing mode may be important in modulating striatal DA release, as shown for burst firing in other preparations.
\end{abstract}

In addition to firing in an irregular interval, single spiking mode, nigral dopamine (DA) cells also fire in bursts. When recorded in chloral hydrate-anesthetized or gallamine-paralyzed animals, these bursts are composed of a series of 2 to 10 spikes of progressively decreasing amplitude and increasing duration (Bunney et al., 1973; Grace and Bunney, 1983a, b). In drug-free, freely moving animals, as many as 23 spikes have been recorded in a burst (Meltzer and Bunney, 1984). Since switching from a regular firing to a bursting mode in other preparations has been correlated with large increases in postsynaptic efficacy (Gillary and Kennedy, 1969a, b) and with neurohormone release in both vertebrate (Hayward and Jennings, 1973; Lincoln and Wakerly, 1974; Dreifuss et al., 1976, 1978) and invertebrate (Gainer, 1972a, b, c; Vincent et al., 1978; van Swigchem, 1979) nervous systems, the mechanism by which DA neurons change from single spiking to bursting was examined. An abstract of these data has been presented (Grace and Bunney, 1983d).

\section{Materials and Methods}

The methods used were the same as detailed in the previous paper (Grace and Bunney, 1984), with the following additions.

Microiontophoresis. During some extracellular recording experi-

${ }^{1}$ We thank Chen-Lun Pun for laboratory assistance and Suzanne Mulready for manuscript preparation. This work was supported in part by United States Public Health Service Grants MH-28849 and MH25642 and by the State of Connecticut.

${ }^{2}$ Present address: Department of Physiology and Biophysics, New York University Medical Center, 550 First Avenue, New York, NY 10016.

${ }^{3}$ To whom correspondence should be addressed. ments, drugs were applied locally to DA neurons by means of microiontophoresis in order to test their effects on the firing patterns of DA neurons. Five-barrel micropipettes were pulled with a Narishige pipette puller, and the center (recording) barrel was filled with $2 \%$ pontamine sky blue dissolved in $2 \mathrm{M} \mathrm{NaCl}$. The three outer barrels were filled with sodium glutamate $(0.2 \mathrm{M}, \mathrm{pH} 8.0)$, tetraethylammonium bromide (TEA, $1 \mathrm{M}$ in $1 \mathrm{M} \mathrm{NaCl}, \mathrm{pH} 7.0$ ), $0.1 \mathrm{~m}$ barium chloride, $0.2 \mathrm{M}$ calcium chloride, $0.2 \mathrm{M}$ cadmium chloride, $0.2 \mathrm{M}$ cobalt chloride, $0.2 \mathrm{M}$ magnesium chloride, or $0.2 \mathrm{M}$ sodium chloride (all at neutral $\mathrm{pH}$ ). A retaining current was applied to retard leakage of the drugs or ions, with alluwances made for the "warmup" effect due to the ionic dilution at the tip of the iontophoretic electrode (Bloom, 1974, 1975).

Interspike interval histograms. Spike trains were analyzed on-line using a PDP 11/34 minicomputer. Interspike interval histograms of 512 bins with binwidths of 1 to 5 msec were collected using the window discriminator output. Simultaneous analysis of burst firing was also performed. Due to the nature of DA cell bursts (i.e., increasing interspike intervals as the burst progresses), the computer was instructed to recognize a burst onset as the concurrence of two spikes with an interspike interval of less than $80 \mathrm{msec}$. Burst termination was defined as an interspike interval greater than $160 \mathrm{msec}$. These values were determined by numerical analysis of a number of digitized single bursts, as described under "Results." Bursts were analyzed for the following components: (1) mean interspike interval within a burst, (2) mean interburst interval, (3) number of burst-related events, (4) number of occurrences of bursts in each burst length category,(5) mean interspike interval relative to the position of spikes in the burst, and (6) postburst inhibition interval with respect to the number of spikes in the burst. Poststimulus time histograms were also generated and analyzed online and off-line.

Intracellular injections of ion-specific compounds. A series of compounds was injected into DA cells in order to identify the ionic currents responsible for mediating their action potential waveform and firing pattern. Intracellular injections were accomplished by filling the recording electrode with the proper solutions and allowing diffusion of 
the compounds under study into the DA cells during recordings. These compounds included: (1) calcium ( $20 \mathrm{~mm}$ calcium chloride dissolved in $3 \mathrm{M}$ potassium acetate), (2) the calcium chelator ethylene glycol bis ( $\beta$ aminoethylether) $-N, N^{\prime}$-tetraacetic acid (EGTA, $0.1 \mathrm{M}$ in $3 \mathrm{M}$ potassium acetate), and (3) the potassium channel blocker TEA (1 $\mathrm{M}$ in $3 \mathrm{M}$ potassium acetate), all at neutral $\mathrm{pH}$.

\section{Results}

Burst firing in DA neurons consisted of trains of two or more spikes occurring within a relatively short interval and followed by a prolonged period of inactivity. Moreover, successive action potentials within the burst were of decreasing amplitude and increasing duration, and the interspike interval tended to increase as the burst progressed. These spontaneously occurring bursts were observed in both extracellular and intracellular recordings from DA cells (Fig. 1).

\section{Extracellular recording}

Determining burst parameters. Burst characteristics were compiled during extracellular recording, since the DA cell-firing
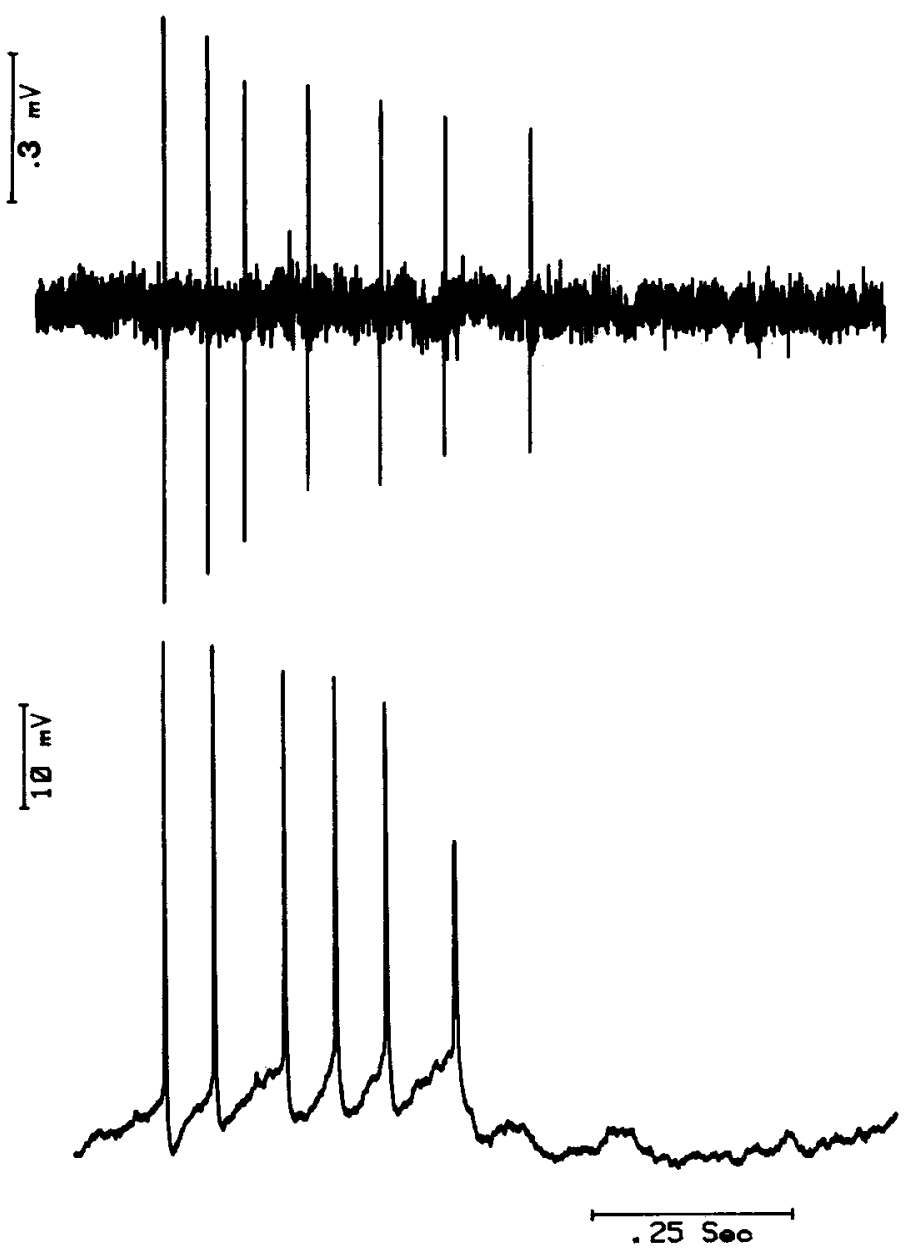

Figure 1. Spontaneus occurring bursts recorded extracellularly and intracellularly in DA neurons. Top, During extracellular recording, DA cells were often observed to fire spontaneous bursts consisting of 3 to 10 spikes of decreasing amplitude and increasing duration. Interspike intervals within the burst were typically near $70 \mathrm{msec}$ and usually increased as the burst progressed. Bottom, DA neurons recorded intracellularly were also observed to spontaneously fire in bursts. The spikes within the burst also displayed progressive increases in duration and decreases in amplitude, with similar temporal relationships as observed extracellularly. The burst was also observed to ride on a depolarizing wave which often extended beyond the last spike in the burst before repolarizing. pattern was considered to be less altered by this recording process than by intracellular recording. Numerical values for determining the beginning and end of a burst were first approximated by digitally analyzing a number of spontancously occurring bursts captured on a digital oscilloscope. All bursts began with a pair of spikes with an interspike interval of 80 msec or less, whereas an interspike interval of this duration rarely occurred in nonbursting cells. The burst upper limit was chosen to be twice this amount for the following reasons: (1) the interspike interval was observed to increase as the burst progressed; (2) occasionally, a spike would be "missed" late in the burst, with subsequent spikes clearly being a part of the same burst (as determined by their relative amplitude and duration), and (3) bursts were always terminated by long periods of silence, thus reducing the chance of a nonburst interspike interval occurring within this range. These values were then tested during computer data acquisition and analysis. Since the on-line computer analysis signaled each time bursts were detected, on-line comparisons of computer-detected bursts could be compared with the audio output of the cells' firing pattern, thus allowing us to determine whether the computer was detecting false positives or missing bursts in its analysis. Secondly, the burst parameters could be varied to allow comparison of the resultant interspike interval standard errors; a large standard error most likely indicating that more nonburst events were scored as bursts. After extensive analysis of a number of parameter combinations ( $N=25$ cells) the assigned values of 80 and $160 \mathrm{msec}$ were determined to agree most closely with our observations of DA cell burst activity.

Burst firing characteristics. Of 75 DA cells analyzed, $55 \%$ demonstrated burst-firing activity, defined in this analysis as having, in addition to a number of shorter two-spike burst doublets, a minimum of two three-spike bursts out of 500 consecutive spikes. This subset of cells was then used to compile burst firing statistics (all statistics are given as mean $\pm \mathrm{SD}$ ). Burst-firing DA cells tended to fire an average of $29 \pm 24 \%$ of their spikes in bursts. The average interspike interval within bursts was $73 \pm 13 \mathrm{msec}$ ( $N=3520$ intervals, 44 cells). However, DA neurons tend to fire in bursts of increasing interspike interval. Thus, when the position of the spike in the burst is taken into account, the first interspike interval $(62 \pm 7 \mathrm{msec}$, $N=44$ cells, 1928 bursts; Fig. 2) was found to be significantly less then the overall interspike interval $(p<0.001)$. Following each burst there was an average postburst inhibitory period of $343 \pm 112 \mathrm{msec}$ ( $N=1803$ bursts) until the next event (spike or burst) was detected. This delay showed a tendency to increase with increasing numbers of spikes within a burst but did not reach statistical significance.

DA neurons fire bursts with a mean length of 2.9 spikes $(N$ $=2190$ bursts), and an average of 40 bursts produced per 500 spikes ( $N=50$ cells). When the burst size data are compiled into a histogram, one can observe that the greatest number of burst events occurs in two-spike burst doublets (Kandel and Spencer, 1961; Calvin, 1974; Benjamin and Swindale, 1975; Calvin and Loeser, 1975; Benjamin, 1978), with bursts of more than six spikes being comparatively infrequent (Fig. $3 A$ ). However, the burst size distribution is different in a rapidly bursting cell. Compiling data from the five cells encountered which displayed more than $70 \%$ of their spikes in bursts, the average number of spikes per burst increases to $3.7(N=486$ bursts, average 96 bursts $/ 500$ spikes; Fig. $3 B$ ), and the distribution of burst sizes is more equitable across bins. In both moderate bursters and rapid bursters, however, there is a rapid dropoff in bursts containing more than six spikes.

Past experience has led us to believe that burst firing is associated with faster firing DA cells-i.e., rapidly bursting cells tended to be firing faster, and drugs which increased DA cell-firing rate tended to increase burst firing as well. However, 
BURST INTERSPIKE INTERVAL

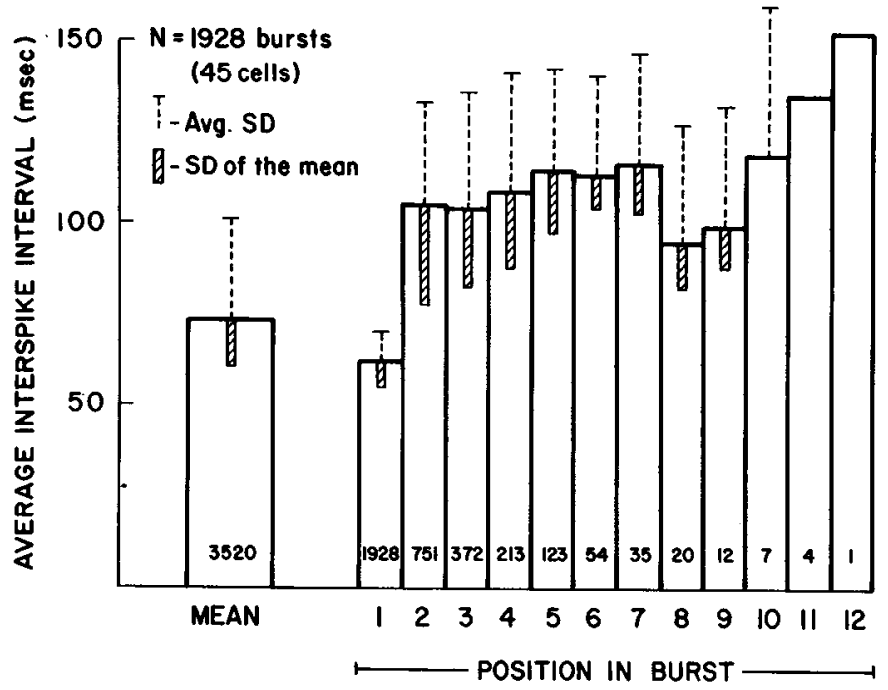

Figure 2. Interspike interval observed between consecutive burstrelated spikes relative to their position within the burst. The mean interspike interval between spikes occurring in bursts was found to be about $70 \mathrm{msec}$. However, if the interspike interval is expressed relative to the position of the interval in the burst, the first interspike interval is found to be significantly $(p<0.001)$ shorter than are the subsequent intervals. In addition, both the variability of this interval within single cells (expressed as average standard deviation) as well as the variability of this interval between different cells (expressed as the standard deviation of the mean) are much smaller than are the same values determined by averaging all interspike intervals without regard to their position. The high variability of subsequent interspike intervals may be due to the inability to analyze the values according to length of the bursts, e.g., the value for the second interspikc interval would be an average derived from three-spike bursts (where this value would be the last interspike interval) as well as from eight-spike bursts (where this interval would still occur relatively early in the burst event). when the base line firing rate of cells is plotted against the percentage of burst firing the DA cells are exhibiting, the correlation is very low $(r=0.38, \mathrm{SE}=20.4, N=75$ cells; Fig. 4). In fact, cases of slowly firing cells displaying higher degrees of bursting, as well as fast cells displaying essentially no burst

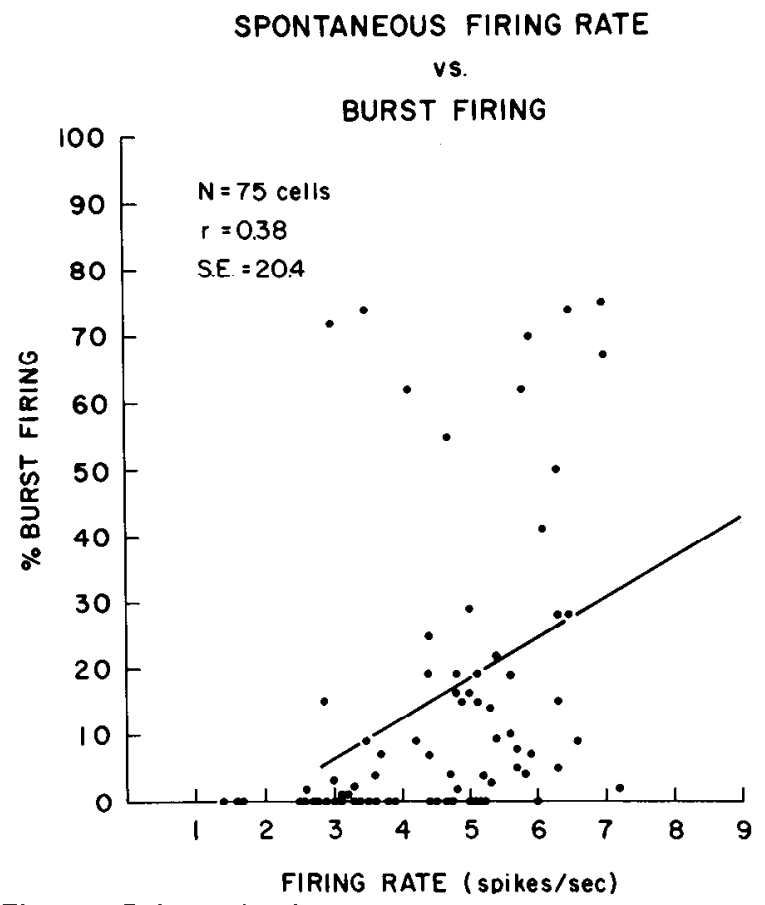

Figure 4. Relationship between DA base line firing rates and the percentage of the spikes occurring in bursts, observed extracellularly. Burst-related spikes were defined as described under "Materials and Methods." Overall, only a low correlation was observed between the base line firing rates of the DA neurons sampled and their degree of burst firing.

\section{BURST SIZE HISTOGRAM}
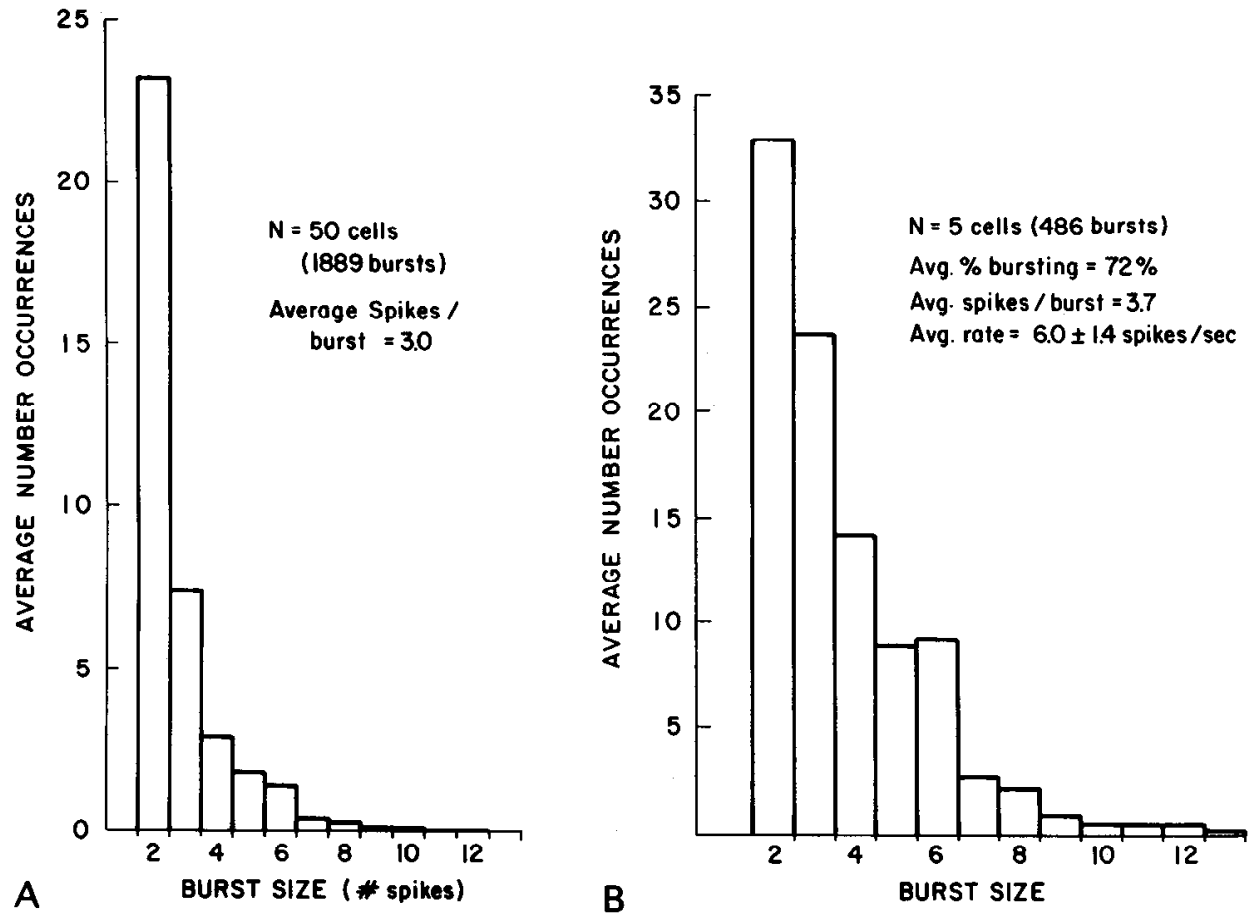

Figure 3. Distribution of burst sizes (number of spikes per burst) occurring spontaneously in DA neurons. $A$, When all burst-firing neurons are taken into account, the average burst was highly skewed toward the smaller-size bursts. $B$, If only cells which fire $70 \%$ or more of their spikes in bursts are included in the histogram, the average burst size increases to 3.7 spikes, with less skewing of the distribution. In both cases, however, a rapid falloff of burst size occurs at the 6 spikes/burst bin. 
activity, were documented (Fig. 5). Thus, there is very little correlation between the base line firing rate and burst firing. However, the story is quite different when the firing rate of an individual cell is considered. When the rate of firing is increased by iontophoresis of the excitatory amino acid glutamate, the increase in firing rate produced by glutamate is highly correlated with the increase in the percentage of burst-related spikes $(N=25$; average increase in rate $=46.8 \pm 8.6 \%$; average increase in bursting $=349 \%$, Table I; correlation of firing with bursting: average $r=0.96 \pm 0.2$, range $=0.92$ to $0.99, p<0.001$, Fig. 6). In addition, the number of spikes per burst increased by $34.5 \%$ ( $p<0.01$, Table I). Similar results were also obtained with cholecystokinin (CCK) iontophoresis onto A10 DA cells. Thus, whereas the base line firing rate of DA cells shows little correlation with the amount of burst firing they are producing, increases in firing rate are highly correlated with this phenomenon.

By using extracellular microiontophoretic techniques, an attempt was made to determine the ionic requirements for burst firing. Because the literature on burst firing in a variety of other preparations indicated an involvement of calcium and/or potassium in its modulation, an investigation using various ionic species known to interact with these ion channels was performed. Since the ions in this set of experiments were applied by extracellular microiontophoresis, the possibility of current contamination of the cell-firing pattern had to be taken into account. To keep current artifacts at a minimum during microiontophoresis, only small ejection currents (i.e., under 5

TABLE I

Effects of iontophoretically administered drugs on DA cell burst firing ${ }^{a}$

\begin{tabular}{lrccc}
\hline $\begin{array}{c}\text { Compound } \\
\text { Iontophoresed }\end{array}$ & $N$ & $\begin{array}{c}\text { Percentage Change } \\
\text { in Firing } \\
\text { Rate }^{b}\end{array}$ & $\begin{array}{c}\text { Percentage Change } \\
\text { in Burst } \\
\text { Firing }\end{array}$ & $\begin{array}{c}\text { Number of } \\
\text { Spikes per } \\
\text { Burst }\end{array}$ \\
\cline { 1 - 4 } Glutamate & 25 & $+46.8 \pm 8.6$ & $+349^{c}$ & $+34.5^{c}$ \\
TEA & 10 & $-1.0 \pm 5.9$ & +69 & +23.0 \\
Barium & 10 & $+28.6 \pm 6.8$ & $+2520^{c}$ & $+59.6^{c}$ \\
Calcium & 17 & $-14.8 \pm 3.1$ & $-67^{d}$ & -7.6 \\
Cobalt & 12 & $+7.6 \pm 6.1$ & +38 & +4.9 \\
Cadmium & 3 & $+52.7 \pm 11.8$ & $+978^{c}$ & $+37.7^{c}$ \\
Magnesium & 3 & $-9.3 \pm 2.2$ & -50 & -14.0
\end{tabular}

${ }^{a}$ Percentages indicate relative change from base line values.

${ }^{b}$ Not included in statistical analysis due to difficulty in determining standard deviation in base line firing rate, since all base line firing rates were normalized to $100 \%$ (mean \pm SD).

${ }^{c} p<0.01$.

${ }^{d} p<0.05$.
A

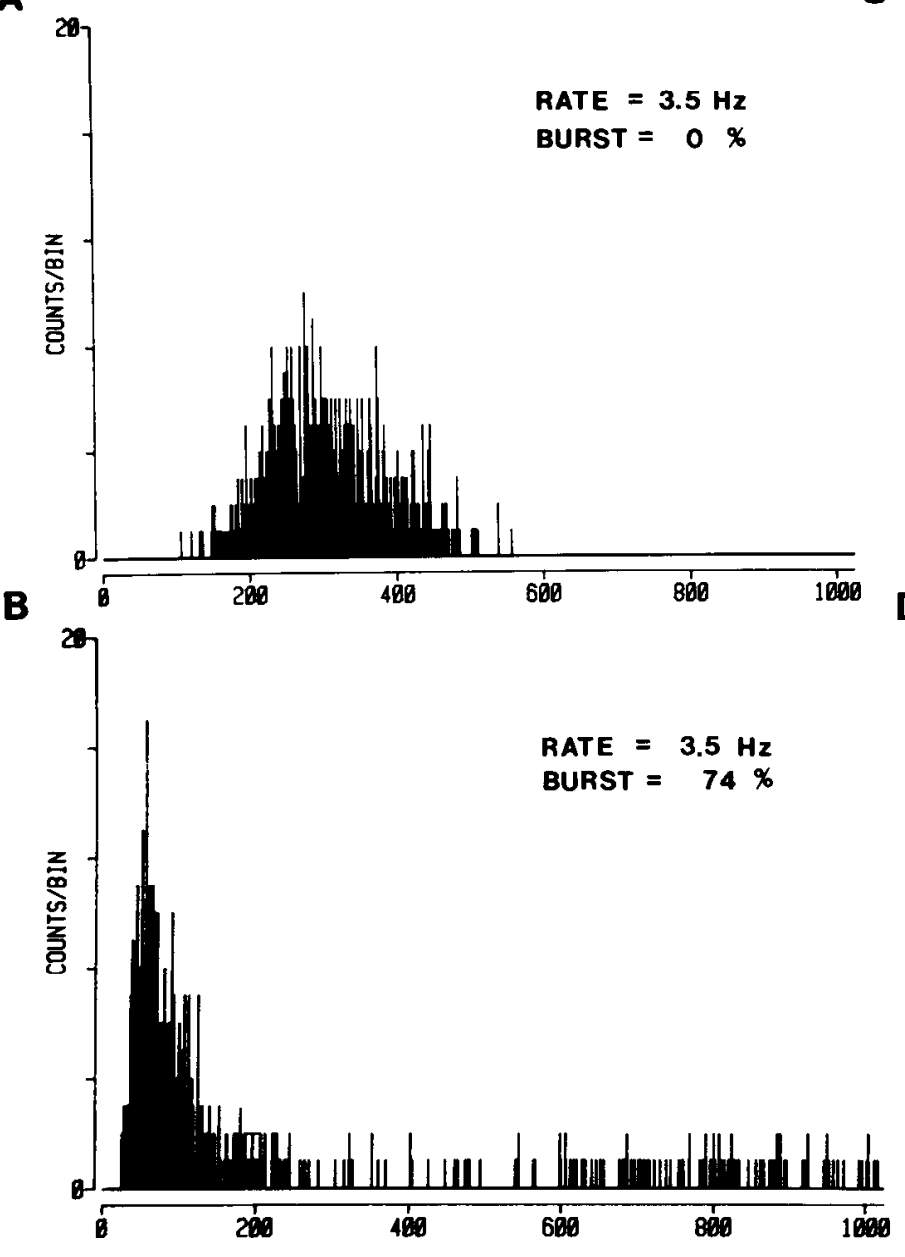

C
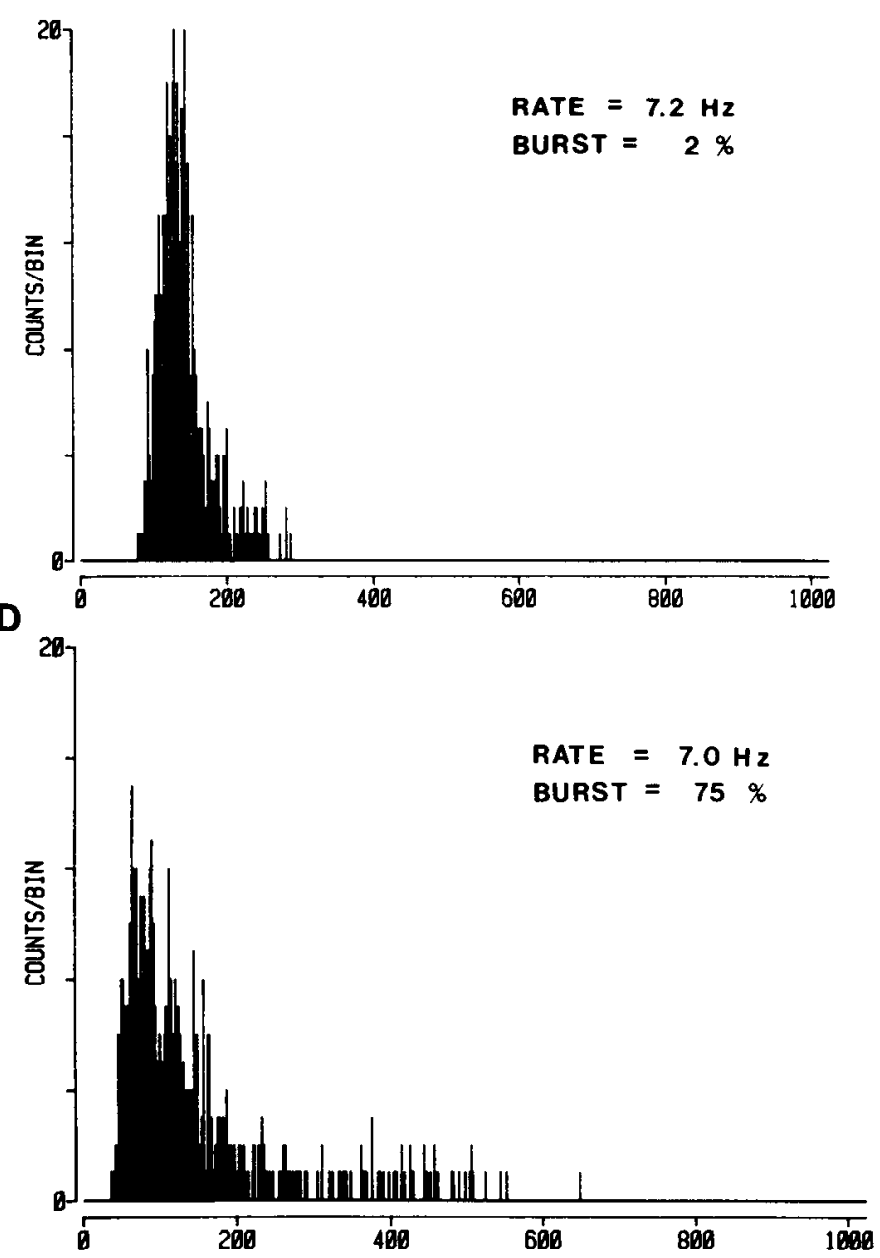

Figure 5. Interspike interval histograms of representative DA neurons demonstrating the independence of firing frequency and degree of burst firing. $A$, A slow-firing DA neuron has a fairly normal distribution of interspike intervals and hence is not burst firing. $B$, In contrast, slow-firing neurons are occasionally observed to fire a large percentage of their spikes in bursts, as can be seen by the skewed distribution of the interspike intervals. Fast-firing DA neurons have also been observed to fire in rapid, even patterns without bursts $(C)$ or in rapid burst-firing patterns $(D)$. 
FIRING RATE VS BURST FIRING

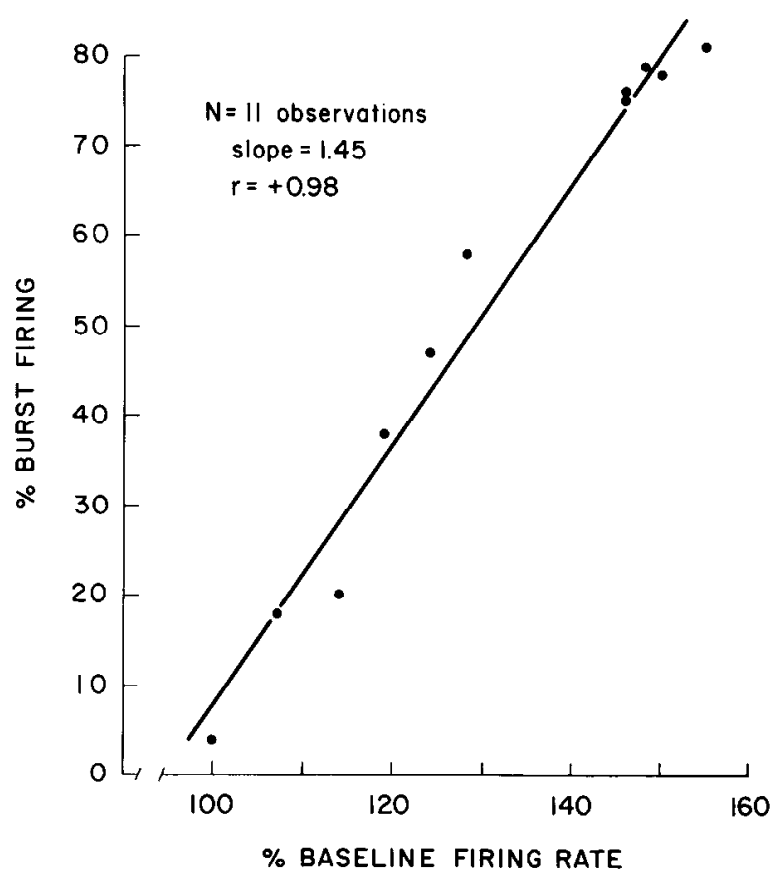

Figure 6. Correlation of changes in DA cell firing rate with burst firing. Increases in the firing rate of this DA neuron produced by glutamate iontophoresis are highly correlated with increases in burst firing frequency. Thus, glutamate iontophoresis increases the firing rate of this cell by $60 \%$, while at the same time increasing burst firing more than 20 -fold. Similar increases in firing rate and burst firing have been observed with systemic haloperidol administration and CCK iontophoresis onto A10 DA cells.

$\mathrm{nA}$; tyically $2 \mathrm{nA}$ ) were used to eject the ions from the pipette. The following divalent cations were used: (1) calcium, to attempt to alter calcium flux across the membrane; (2) magnesium, to control for the "membrane-stabilizing" properties of calcium (Frankenhauser and Hodgkin, 1957; Hillman and McIlwain, 1961); (3) cobalt and (4) cadmium, which are calcium channel blockers; and (5) barium, an ion known to enter cells through calcium channels and block potassium channels intracellularly. In addition, the potassium channel blocker TEA was also tested.

Both calcium and magnesium tended to decrease the amount of bursting compared to controls ( $39.2 \%$ of base line, $n=17$, and $50.0 \%$ of base line, $N=5$, Table I), although only the decreased burst firing produced by calcium iontophoresis reached statistical significance $(p<0.05)$. Both calcium and magnesium also caused some decreases in firing rates $(14.8 \%$ and $9.3 \%$ of base line, respectively; Table I). Thus, it was impossible to distinguish changes in bursting induced by the effects of these ions on firing rate from their direct effects on burst mechanisms.

Cobalt iontophoresis caused a nonsignificant rise in bursting (38.2\% increase, $N=12$ ) in addition to a small increase in firing rate $(7.6 \%$, Table I). In addition, despite the small number of times it was successfully applied $(N=3)$, another calcium antagonist, i.e., cadmium, caused a significant increase in the percentage of burst-related events ( $978 \%$ increase over base line, $p<0.05$, Table I) and induced a $53 \%$ increase in firing rate. Although this represents a large increase in bursting induced by cadmium over that seen even with glutamateinduced bursting, each application of cadmium was associated with a large amount of electrical noise. It is possible that cadmium may be acting in a manner other than calcium block- ade, since the calcium blocker cobalt did not mimick these actions.

Barium had very strong effects on the degree of burst firing. Bursting was increased an average of $2520 \%$ over base line frequency $(N=10, p<0.001$, Fig. 7$)$, whereas firing rate was increased only $28.6 \%$. Barium also caused a $59.6 \%$ increase in the average number of spikes in a burst ( $p<0.01$, Fig. 7). TEA, however, had little effect on bursting when administered by extracellular microiontophoresis. Overall, TEA applied extracellularly resulted in a nonsignificant increase in burst firing ( $69 \%$, range $=-35 \%$ to $+132 \%, N=10)$. This was accompanied by little change in firing rate, although cells often demonstrated a tendency toward decreased amplitude and increased duration spikes without an increase in firing rate.

Thus, the above data suggest that the degree of burst firing, while not necessarily showing a correlation with the base line firing rates of DA neurons, is strongly affected by changes in firing rate. In addition, barium markedly increases the percentage of spikes occurring in bursts. Since barium is known to interact with both calcium and potassium channels, an investigation into burst firing using intracellular recording techniques was performed in order to try to distinguish the conductance changes involved in the initiation of burst firing.

\section{Intracellular recording}

Since increasing the firing rate of DA neurons by glutamate effectively increased the amount of burst firing observed during extracellular recording, the effects of depolarization on DA neuron firing patterns during intracellular recording was tested. Unlike other systems, a burst could never be triggered by a short (i.e., $25 \mathrm{msec}$ ) depolarizing pulse, regardless of whether or not the cell was bursting spontaneously. Longer depolarizing pulses (i.e., 100 to $200 \mathrm{msec}$ ), however, had a differential effect on bursting versus non-bursting cells-a square pulse produced a series of equal amplitude spikes which accommodated quickly in nonbursting DA neurons, whereas bursting neurons responded by firing spikes of decreasing amplitude which often progressed to spike inactivation. This differential effect proved

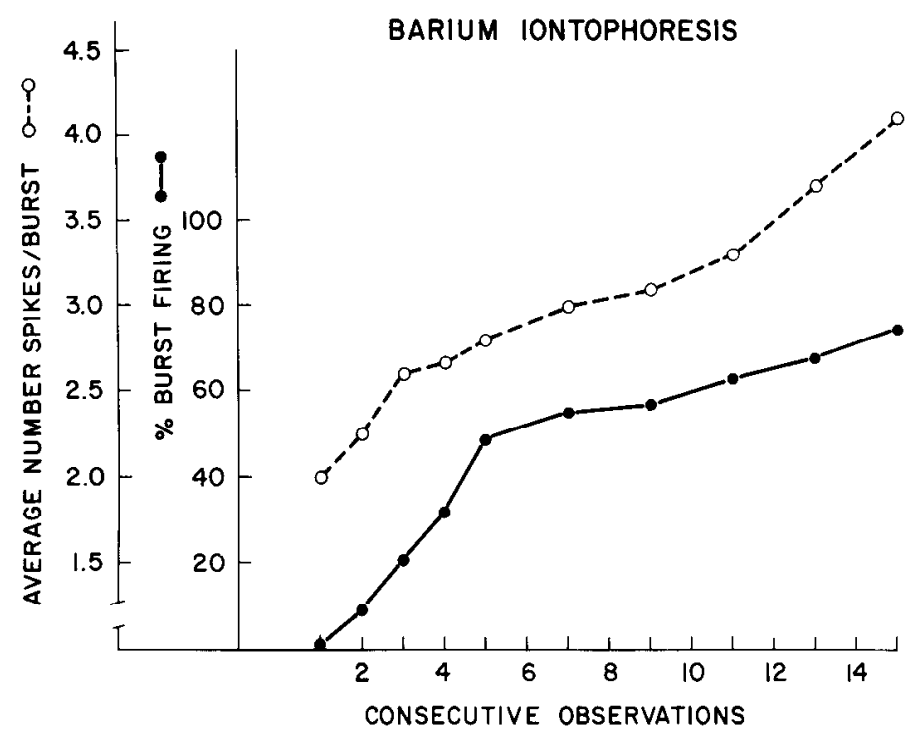

Figure 7. Effects of barium iontophoresis on DA cell burst firing. lontophoretically applied barium resulted in a progressive increase in the percentage of spikes occurring in bursts, as indicated by the solid line. In addition, barium also resulted in an increase in the length of the bursts, as shown by the dashed line. Thus, the increased burst firing produced by barium resembles bursting seen in DA cells with high levels of base line burst activity; i.e., increases in burst firing are associated with increases in the number of spikes per burst. 
reliable in determining whether a DA cell is in a burst-firing mode. Long-term intracellular injection of depolarizing current (between 0.3 and $0.5 \mathrm{nA}$ applied for periods of time on the order of minutes) reliably caused all non-burst-firing DA neurons tested to fire in bursts $(N=9$, Fig. 8$)$. Bursts were up to six spikes in length and had interspike intervals of approximately 65 msec. The spikes within each burst were of decreasing amplitude and increasing duration, as seen extracellularly in spontaneously bursting neurons. Fach spike was found to be riding on a depolarizing wave. There was still a large afterhyperpolarization (AHP) present following spiking, both before and during depolarization (Fig. $8 B$ ), although it was difficull to estimate whether they differed in size from control AHPs due to the voltage dependency of the response (Gorman and Thomas, 1980; Hofmeier and Lux, 1981; Woolum and Gorman, 1981; Adams et al., 1982; Lux and Hoffmeier, 1982). Thus, it could not be determined whether the calcium-activated potassium conductance $\left(I_{\mathrm{K}(\mathrm{CA})}\right)$ was altered during the transition to burst firing. All responses demonstrated a time-dependent reversal upon repolarization of the neuron.

Resistances estimated by depolarizing pulses are typically less than resistance measurements obtained with hyperpolarizing pulses, due to activation of rectifying potassium conductances by the depolarization (Lewis and Wilson, 1982). Thus, depolarization of DA neurons resulted in decreases in membrane input resistances. However, if the depolarizations were maintained, a gradual return of the input resistance to base line resistance values was observed $(N=5$, Fig. 9$)$. This change was typically associated with the onset of burst firing.

Thus, burst firing can be initiated by depolarizing current injection and is typically accompanied by a time-dependent increase in input resistance. Depolarization, under these conditions, could elicit burst firing in at least two ways: (1) by directly affecting the membrane properties of the DA cell, or (2) by increasing spike frequency and thereby affecting the membrane indirectly. Such a spike-related mechanism could act through increased calcium influx. Therefore, calcium was injected into DA neurons to study its effects on firing pattern.

Calcium was found to induce burst firing rapidly in all cells tested $(N=6)$. Within 5 to $10 \mathrm{~min}$ after penetration with a calcium-containing electrode, DA neurons began firing in a bursting pattern. The resultant pattern had an interspike in-
A $\int^{E}$

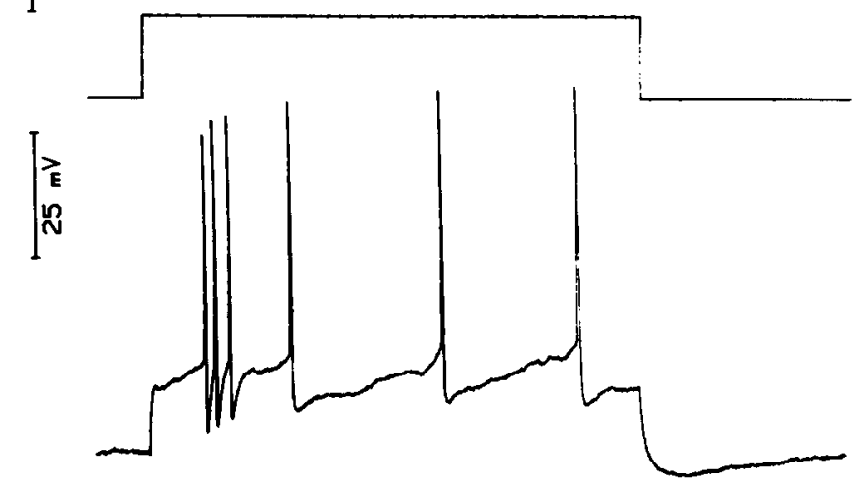

.1500

C

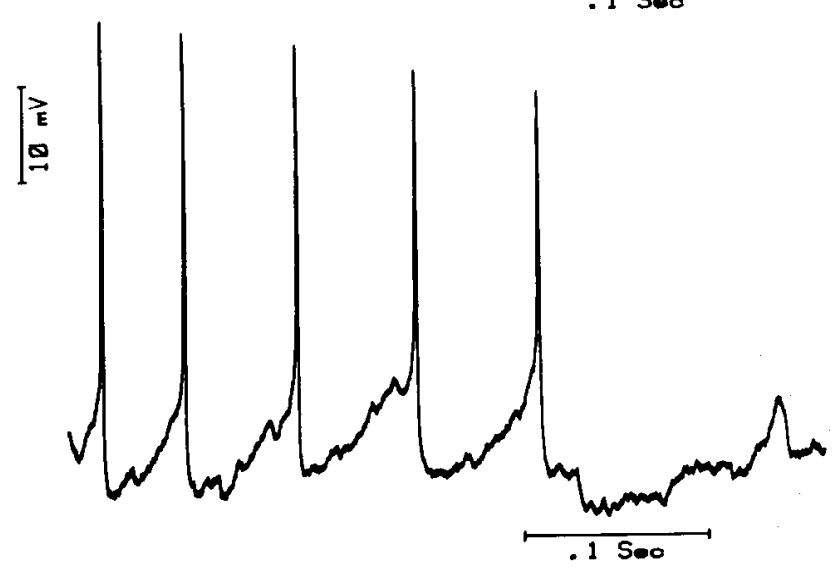

B

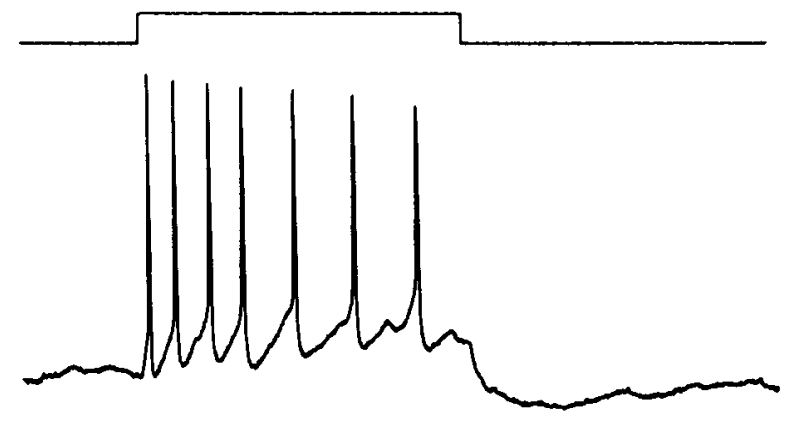

.2500

D

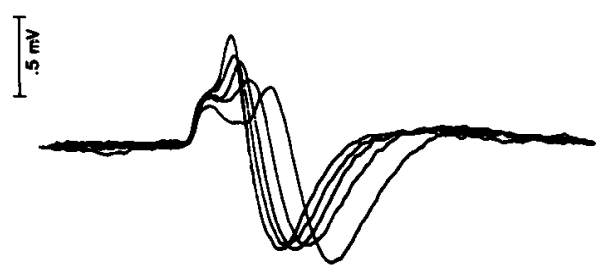

$1.0 \mathrm{msec}$

Figure 8. Effects of long-term depolarizing current injection on the firing pattern of DA neurons recorded intracellularly. A, Control response of a nonbursting DA neuron to a depolarizing pulse $(1.5 \mathrm{nA})$. The resultant spike train shows little change in spike amplitude, in addition to demonstrating a progressive accommodation to the excitatory stimulus. These features are characteristic of control responses elicited in DA neurons in response to depolarizing stimuli. $B$, Following long-term depolarization (e.g., to $-48 \mathrm{mV}$ membrane potential for a period of $3 \mathrm{~min}$ or more), a smaller amplitude depolarizing pulse $(0.5 \mathrm{nA})$ produces a larger number of spikes displaying progressively increased duration and decreased amplitude. The AHP occurs at the termination of the depolarizing pulse in the normal manner. $C$, A spontaneously occurring burst in a DA neuron induced to burst fire by depolarization. This burst has the characteristic progressively increased duration and decreased amplitude spiking typically associated with DA cell bursts. $D$, Overlay of spontaneously occurring DA cell spikes recorded extracellularly during hurst firing, to illustrate the changes in spike shape observed in burst-firing DA cells. 
RESISTANCE CHANGES WITH DEPOLARIZATION INDUCED BURSTING

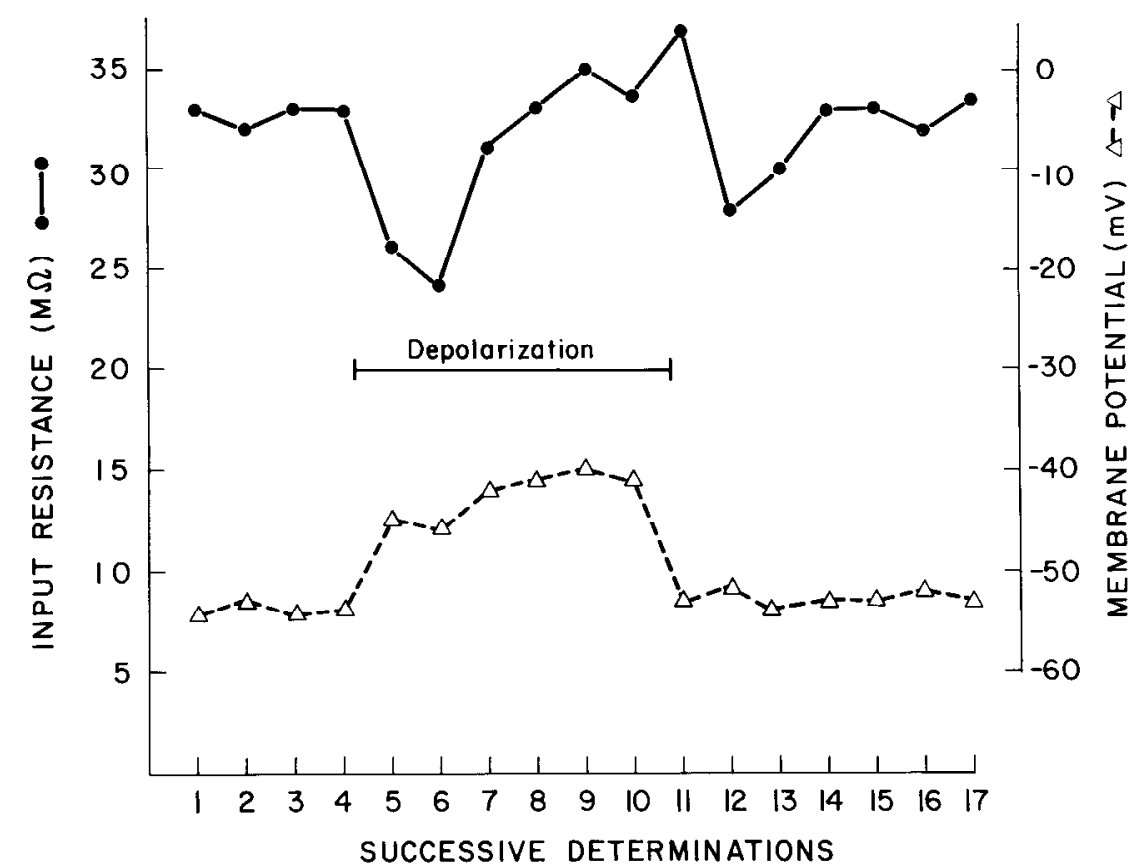

Figure 9. Effects of depolarizing current injection on the membrane potential and input resistance of DA cells during intracellular recording. Intracellular injection of depolarizing current $(0.25 \mathrm{nA}$ at bar) depolarized the membrane potential (dashed line) and decreased the input resistance (solid line) of this DA cell, as reported for many other preparations during accommodation responses. However, as the depolarization is maintained, the input resistance gradually increases to and surpasses control levels. This is typically associated with an increase in burst firing in DA cells. A corresponding increase in the level of depolarization also occurs secondary to this increase in input resistance, suggesting a decreased conductance to ions with reversal potentials negative to the membrane potential. Cessation of the depolarizing stimulus results in repolarization of the DA cell and subsequent normalization of the input resistance. Time between determinations was typically 0.5 to $1.5 \mathrm{~min}$

terval $(64 \pm 11 \mathrm{msec})$ which was similar to that observed extracellularly in spontaneously bursting DA cells. Intracellular injection of calcium was found to be the most potent manipulation tested in increasing burst firing in DA cells. Depolarizing pulses elicited a train of spikes of decreasing amplitude and increasing duration, even when the soma was hyperpolarized well below firing threshold (Fig. 10). This response was not due to the leakage of a small amount of chloride from the calcium chloride electrodes, since electrodes filled with 3 m potassium chloride did not affect burst firing or the response to a depolarizing pulse. Calcium-induced bursts contained six to eight spikes and resulted in averages of $47 \%$ of the spikes occurring in burst-related events in DA cells which were initially nonbursting (Fig. 11). Interspike intervals of spikes occurring within bursts centered around $65 \pm 20 \mathrm{msec}$. No significant alteration of the membrane potential was noted at the onset of burst firing with injection of this ion (resting potential $=54.0$ $\pm 4 \mathrm{mV}$, mean $\pm \mathrm{SD}$ ). Furthermore, no inactivation of the $I_{\mathrm{K}(\mathrm{CA})}$ could be observed, since AHPs following depolarizing pulses were still present and even demonstrated a trend toward increased amplitude over control conditions. However, cells impaled with calcium-containing electrodes demonstrated a degradation of spike amplitude and typically inactivated upon long-tcrm impalements. Although this effect could not be dissociated from possible injury, it was consistently observed with each stable, long-term impalement of DA neurons with calciumcontaining electrodes.

Thus, it appears that calcium influx induced by increases in spike frequency results in an initiation of burst firing. In order to substantiate the calcium requirement for burst firing, the effects of intracellular injection of the calcium chelator EGTA on depolarization-elicited bursting were tested. EGTA injection into DA cells resulted in an increase in the excitability of the cells in response to depolarizing pulses. However, in each case, all elicited spikes were of equal amplitude and duration and occurred at nearly equal interspike intervals - a result very different from that seen during burst firing. Even long-term depolarization and large amplitude pulses did not trigger bursts or decreasing amplitude spikes ( $N=9$, Fig. 12). Typically, longterm depolarization in the presence of EGTA resulted in inactivation of spontaneous discharge altogether.

Thus, depolarization appears to lead to burst firing by increasing spike frequency which, in turn, leads to an increase in calcium influx. This calcium influx may be indirectly responsible for the increase in input resistance observed with the onset of bursting. Although the conductances altered by calcium influx could not be directly determined, drawing from these results, one possible manner in which calcium could lead to an increase in burst firing is by inactivation of a depolarizationelicited potassium conductance. This interpretation is consistent with the barium-induced bursting reported above, as well as the observed increase in input resistance which occurs at the onset of bursting. Thus, in order to determine whether potassium may also play a role in burst firing, the responsc of DA cells to intracellular injection of the potassium blocker TEA was evaluated. Intracellular injection of TEA consistently produced burst firing soon after impalement (less than 5 min, $N$ $=6$ ). Spikes demonstrated a decreasing amplitude/increasing duration spike train in response to a depolarizing pulse (Fig. 13). Furthermore, all of these changes preceded the TEA- 
A

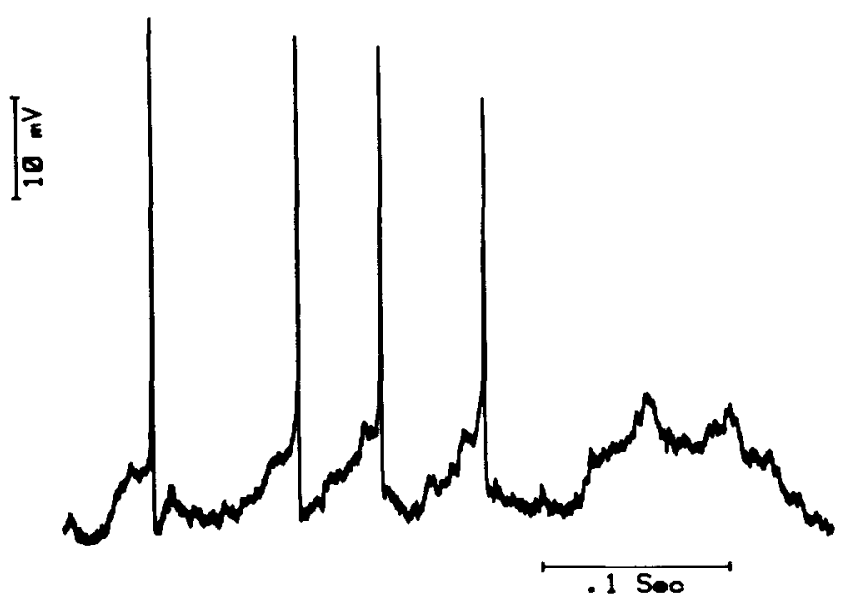

B
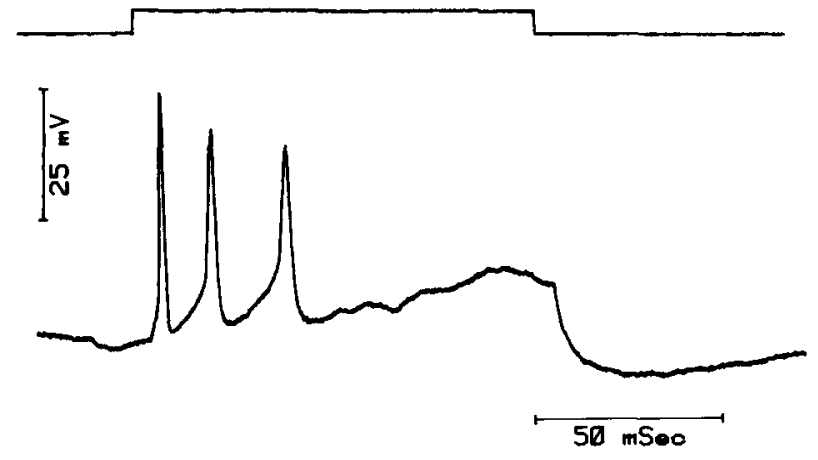

C

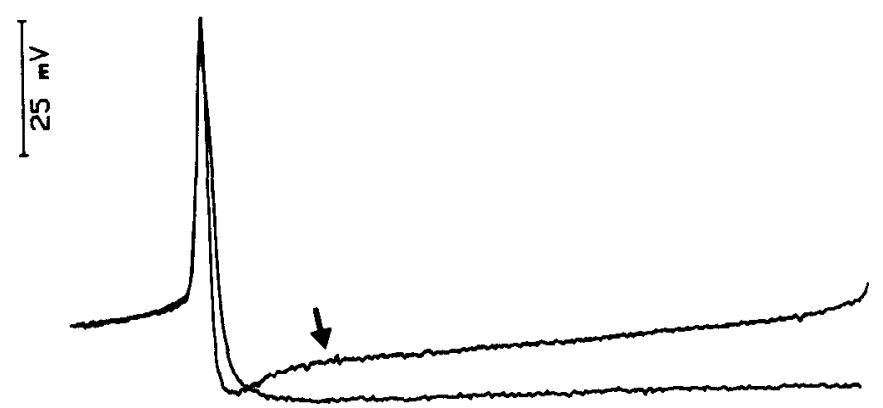

$10 \mathrm{mS}$

Figure 10. Effects of intracellular calcium injection on DA neuron electrophysiology. Impalement of a DA neuron with an electrode containing calcium chloride $(20 \mathrm{mM})$ leads to initiation of spontaneous burst firing $(A)$. The DA neuron also responds to a depolarizing pulse $(0.5 \mathrm{nA})$ in a manner consistent with the burst firing mode $(B)$; i.e., with spikes of increasing duration and decreasing amplitude. Burst firing appears to be maintained by a depolarizing wave following a prior burst-related spike. Thus, although this wave is absent following spikes prior to the injection of calcium ( $C$, hottom trace), the depolarizing wave can be observed to develop during bursting following calcium injection (arrow).
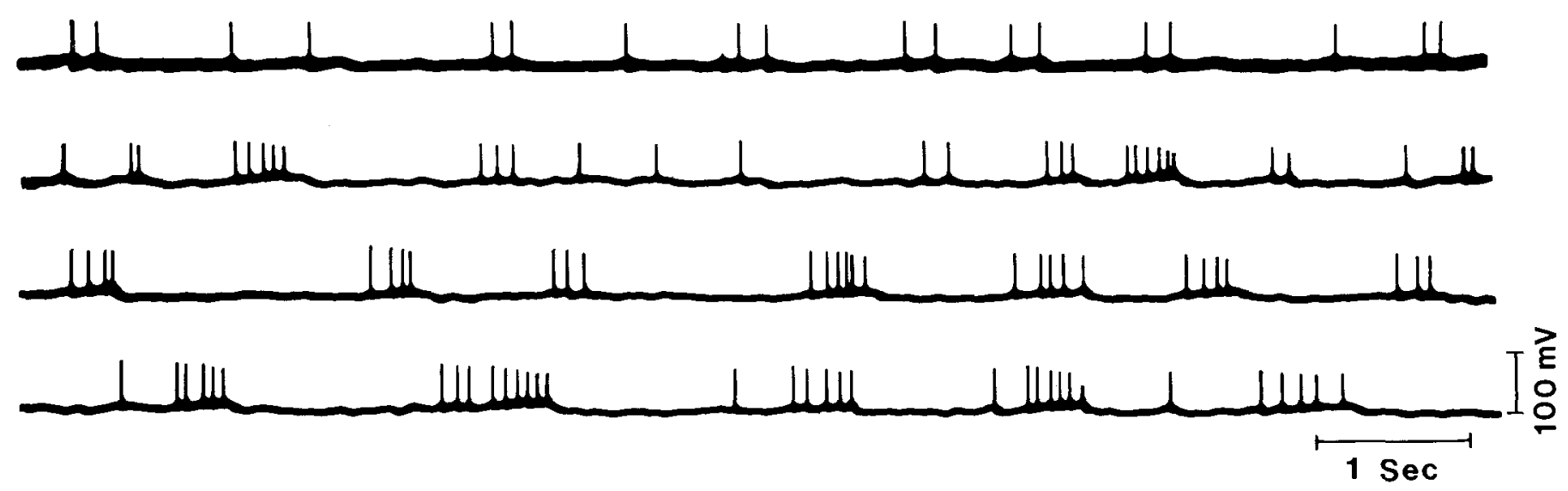

Figure 11. Effect of intracellular calcium injection on the firing pattern of nigral DA cells. In the first few minutes following impalement with a calcium-containing electrode, the stabilized DA cell demonstrates its typical slow, single spike firing pattern (top trace). As calcium leaks from the electrode into the cell, the pattern slowly changes over the next 10 to 20 min into a burst-firing pattern (second through fourth trace).

induced blockade of the AHP. Actually, continued intracellular injection of TEA to the point of inhibition of the AHP often resulted in a decreased tendency to fire in bursts (Fig. 13B). This decrease in bursting usually required intracellular injections of TEA for $30 \mathrm{~min}$ or longer. TEA also resulted in dramatic increases in membrane input resistances, as expected. Membrane resistances increased up to 101 megohms (mean $=$ $80.2 \pm 15.0$ megohms, $N=6$, Fig. 14), although resistance increases of this magnitude required stable intracellular penetrations with TEA-containing electrodes for periods of 30 to 60 


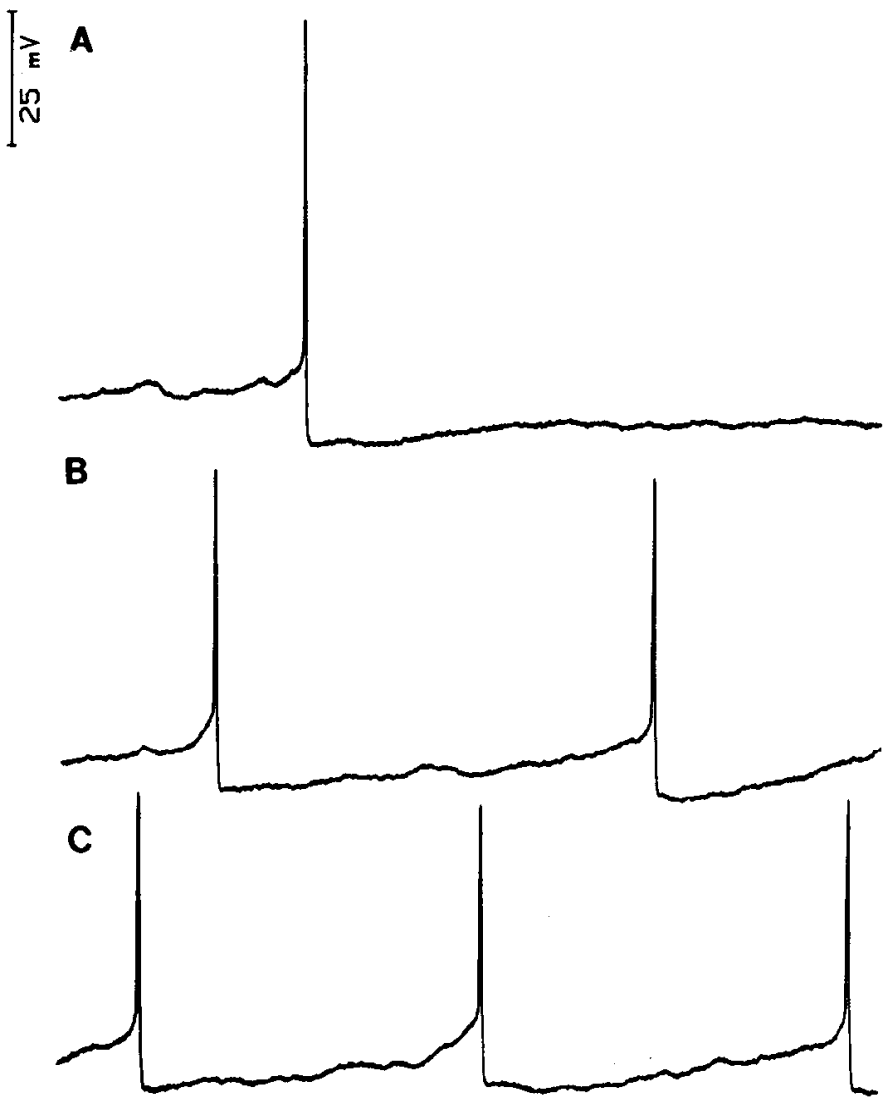

1 Sec

Figure 12. Fffect of intracellular injection of the calcium chelator EGTA on depolarization-elicited burst firing in DA neurons. After injection of EGTA, injection of progressively increasing levels of constant depolarizing current $(A$ to $C$ ) increases the firing rate of this DA neuron, as can be observed by the decreased interspike interval. However, in the presence of intracellular EGTA, the long-term depolarization does not alter its firing paltern. Instedd of initiating a burst-firing pattern, the DA cell retains its pacemaker-like firing characteristics and merely fires at a faster rate in response to increasing levels of depolarization (membrane potentials are $-56 \mathrm{mV},-46 \mathrm{mV}$ and -42 $\mathrm{mV}$, respectively). Even when the DA cell is depolarized to the point where spontaneous activity ceases, a depolarizing pulse is still unable to produce the characteristic changes in spike shape typical of DA cells capable of firing in bursts (not shown).

minutes or longer. The cells also depolarized in response to long-term TEA injection (average resting potential $=47 \pm 3$ $\mathrm{mV}$, as compared to control levels of $55 \pm 2.9 \mathrm{mV}$ ) but still fired action potentials spontaneously.

\section{Discussion}

DA neuron burst firing in gallamine-paralyzed or chloral hydrate-anesthetized rats consists of spike trains typically containing three to six action potentials, with each consecutive spike displaying a progressive increase in duration and decrease in amplitude. The spikes occurring within bursts exhibit comparatively short (i.e., 60 to $70 \mathrm{msec}$ ) interspike intervals and are terminated by longer periods of inactivity. More than half of the DA neurons sampled displayed some burst activity (defined as at least two three-spike bursts during a 500-spike period). Bursting DA neurons fire about $30 \%$ of their action potentials in bursts, with a maximum observed percentage of burst-related spikes being $74 \%$. The average burst consists of about three spikes, with rapidly bursting ncurons emitting an average of four spikes per burst.

Burst firing in DA neurons has classically been associated with the faster firing cells. However, there is little correlation between rate of bursting and base line firing rate. On the other hand, burst firing is very well correlated with changes in firing rate. Thus, GABA iontophoresis (Aghajanian and Bunney, 1977) and intravenous apomorphine administration (Grace and Bunney, 1983a) both caused DA cells to stop firing in bursts, whereas glutamate or CCK iontophoresis, intravenous antipsychotic drugs, and long-term intracellular depolarization caused nonbursting DA neurons to begin burst firing. These depolarization-initiated bursts are similar in size and interspike interval to those seen in spontaneously bursting DA cells.

To investigate the ionic mechanisms underlying burst firing, the influence of extracellularly administered ions on DA cell bursting was investigated. Calcium, administered extracellularly, produced a trend toward decreased burst firing. However, this decrease in bursting may have been mediated through a decrease in excitability, which has been associated with extracellular calcium administration (Frankenhauser and Hodgkin, 1957; Hillman and McIlwain, 1961; Krnjevik, 1965; Kato and Somjen, 1969; Kelley et al., 1969; Hahin and Campbell, 1983). In other systems, this decrease in excitability appears to be mediated by an action on a voltage-dependent sodium channel rather than a hyperpolarization or a change in conductance (Brink, 1954; Blaustein and Goldman, 1966; Kelley et al., 1969).

Of the ions tested, barium proved most effective in producing burst firing in DA neurons. Barium is known to act by entering the cell via calcium channels (Hagiwara et al., 1974; Eckert and Lux, 1976; Connor, 1977; Gola et al., 1977; Magura, 1977) and subsequently blocking voltage-dependent (Hermann and Gorman, 1979; Adams and Gage, 1980) and calcium-dependent (Gola et al., 1977; Magura, 1977; Gorman and Hermann, 1979; Hermann and Gorman, 1979; Adams and Gage, 1980) potassium conductances (Eaton and Brodwick, 1978, 1980; Stanfield and Standen, 1978; McAfee and Yarowsky, 1979; Armstrong and Taylor, 1980). In the hippocampus, barium was also found to increase burst firing (McAfee and Yarowsky, 1979; Johnston et al., 1980; Hotson and Prince, 1980, 1981; Hablitz and Johnston, 1981; Brown and Griffith, 1983a, b). The lack of efficacy of manganese (a calcium channel blocker) in duplicating this response led some authors to conclude that the ability of barium to induce burst firing in the hippocampus is dependent on its actions on potassium channels other than those activated by calcium (Hotson and Prince, 1980). Barium also increased the spike durations of DA cells, as has been reported in other preparations (McAfee and Yarowsky, 1979; Adams and Gage, 1980; Hotson and Prince, 1980, 1981).

Burst firing in DA neurons was not strongly affected by the extracellular administration of calcium blockers, such as cobalt. Cadmium did cause an increase in burst firing, but recent evidence indicates that cadmium may block a voltage-dependent potassium current $\left(I_{K(\omega)}\right)$ as well as the calcium-dependent currents (Kostyuk and Krishtal, 1977). The small increase in burst firing obtained with cobalt may arise from a separate phenomenon. Thus, in some systems external calcium blockade by cobalt was shown to be ineffective in eliminating calciummediated effects, since calcium can be stored and released internally (Akaike et al., 1983). The depolarization-elicited release of calcium has been described in preparations in which the neuronal ultrastructure has been characterized by the presence of numerous subsurface cisternae as well as large amounts of endoplasmic reticulum (Rosenbluth, 1962; Henkart et al., 1976; Endo, 1977; Henkart and Nelson, 1979; Akaike et al., 
A

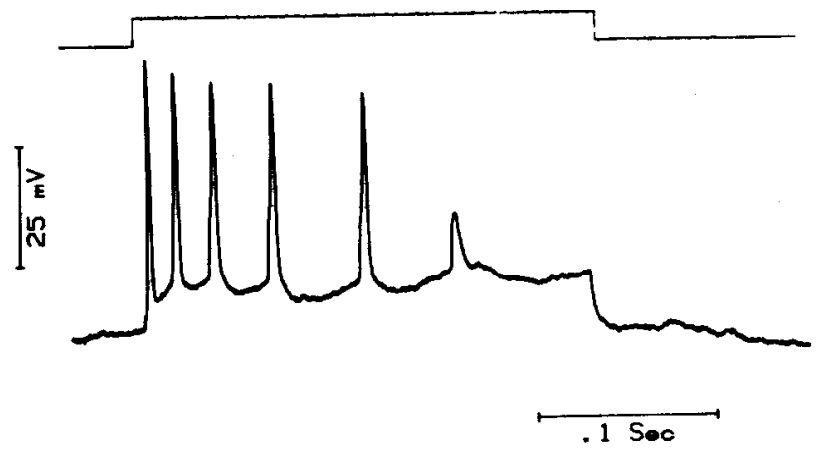

C

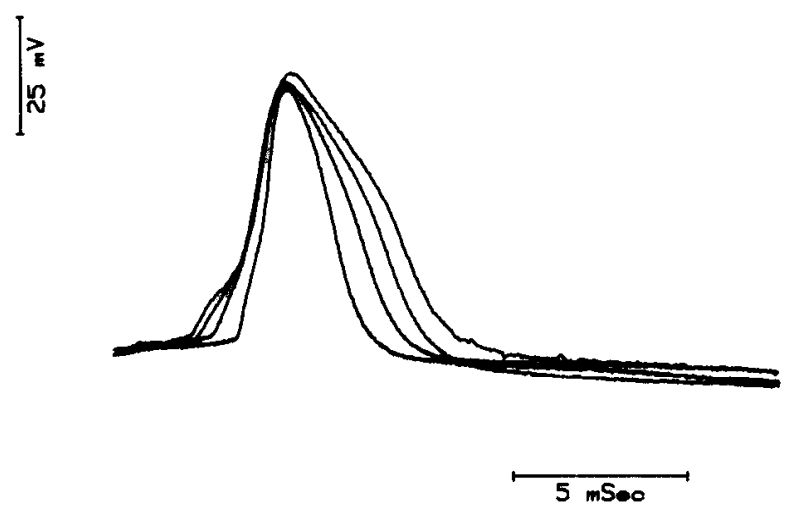

B

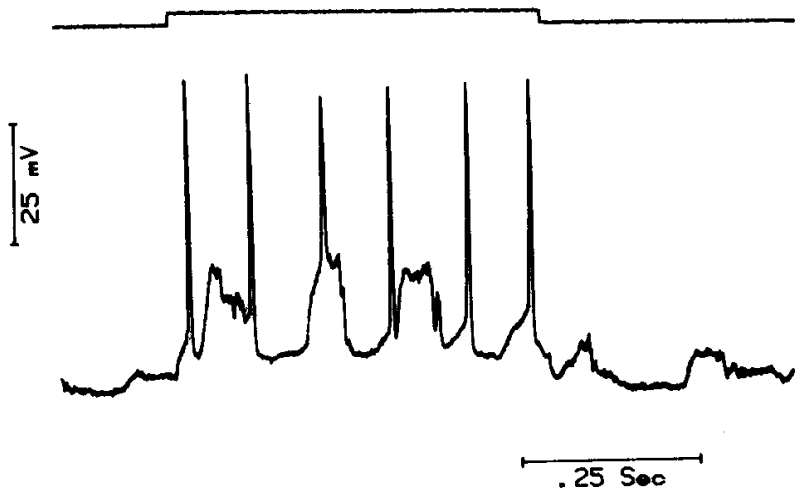

D

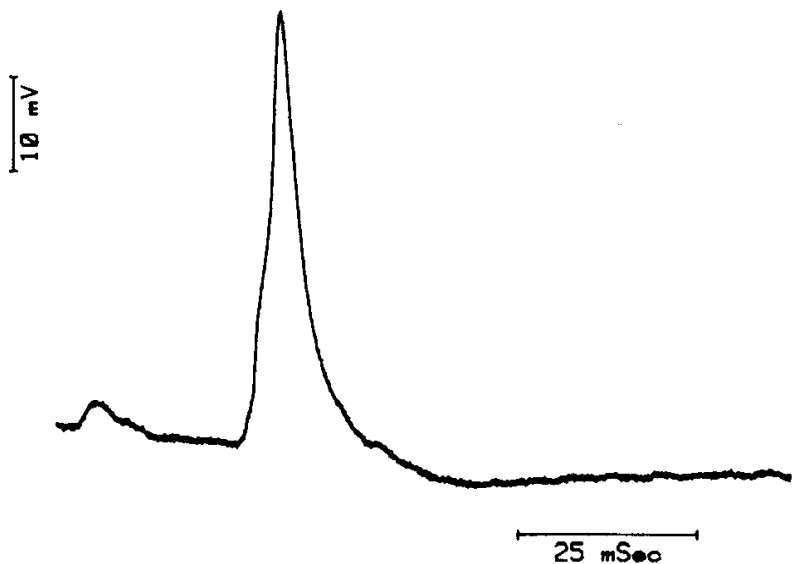

Figure 13. Effects of intracellular injection of the potassium blocker TEA on DA neuron electrophysiology. During early periods of TEA injection (i.e., $15 \mathrm{~min}$ or less) $(A)$, DA neurons respond to a depolarizing current pulse $(0.55 \mathrm{nA})$ in the same manner as observed after long periods of depolarization - with a series of decreasing amplitude/increasing duration spikes. Spontaneous burst firing is also observed during this period (not shown). In addition, the DA cell action potential gradually increases in duration $(C)$, primarily due to the appearance of a shoulder on the repolarizing phase of the action potential. These effects have been typically associated with preferential blockage of an $I_{\mathrm{K}(v)}$ in other preparations. In contrast, after long periods of TEA injection ( $45 \mathrm{~min}$ or more), a very small depolarizing pulse ( $0.22 \mathrm{nA}$ ) now triggers a series of spikes of nearly equal amplitude and duration $(B)$. This is usually associated with blockade by TEA of the less sensitive $I_{\mathrm{K}(\mathrm{Ca})}$. The action potentials still continue to increase in duration; however, the increased duration is now due to a slower repolarization toward base line rather than to accentuation of a shoulder on the fulling phase of the spike $(D)$. These data are consistent with the interpretation that TEA first increases burst firing by blocking a TEA-sensitve $I_{\mathrm{K}(v)}$ but will eventually decrease burst firing by inhibiting the $I_{\mathrm{K}(\mathrm{Ca})}$.

1983). Indeed, one group of investigators has observed internal calcium release, transport, and binding to the cell membrane at the onset of pentylenetetrazol-induced bursting in snail neurons (Sugaya and Onozuka, 1978a, b, c; Sugaya et al., 1978, 1981a, b, 1982). Morphologically, DA neurons have been characterized as containing inordinately large amounts of endoplasmic reticulum and cisternae (Rinvik and Grofovà, 1970; Gulley and Wood, 1971; Sotelo, 1971; Hökfelt and Ungerstedt, 1973; Sotelo and Riche, 1975; Domesick, 1979, 1981; Hattori et al., 1979; Mercer et al., 1979; Stinus et al., 1981; Wassef et al., 1981; Linder et al., 1982; Groves and Linder, 1983). The zona compacta of the substantia nigra also has high levels of calcitonin-binding (Henke et al., 1983; Olgiati et al., 1983) and calcium-binding protein (Feldman and Cristakos, 1983). In addition, $\mathrm{x}$-ray microanalysis has shown DA cells to contain inordinately high levels of calcium (Wood et al., 1983). However, internal release of calcium has never been demonstrated in this class of cells, thus making any generalization to the calcium release phenomenon described in invertebrates purely speculative. Nevertheless, such a mechanism is consistent with our observation of burst induction by external calcium blockers as well as by intracellular calcium administration.

Burst firing can also be initiated by manipulation of intracellular ions and conductances. Thus, intracellular administra- tion of calcium will lead to bursting, whereas EGTA not only blocks spontaneous bursting, but also prevents depolarization from inducing burst firing. Long-term depolarization (on the order of minutes) results in bursting apparently due to the intracellular accumulation of calcium ions, which entered the neuron during spiking. This may imply that, during a normal firing state, the intracellular calcium is at a steady-state concentration, being effectively buffered by fast reuptake mechanisms (Lehninger, 1970; Carafoli and Crompton, 1978; Borle, 1981; Blaustein and Nelson, 1982; Fiskum and Lehninger, 1982). However, depolarization may increase the spike-dependent calcium influx enough to overwhelm the various cellular calcium uptake mechanisms and thus be capable of initiating a second response - that of burst firing. Although a mechanism of calcium action in initiating burst firing cannot be derived from our data without additional experiments, one possible mechanism suggested by our data is that the increased intracellular calcium levels may elicit bursting by decreasing a voltage-dependent potassium conductance. This speculation is based on the following evidence: (1) the depolarization-elicited decrease in input resistance (Lewis and Wilson, 1982) is followed by an increase in input resistance and a further depolarization after the onset of bursting; (2) the potassium channel blockers barium (applied externally) and TEA (applied inter- 
TEA

\section{CURRENT INJECTED}

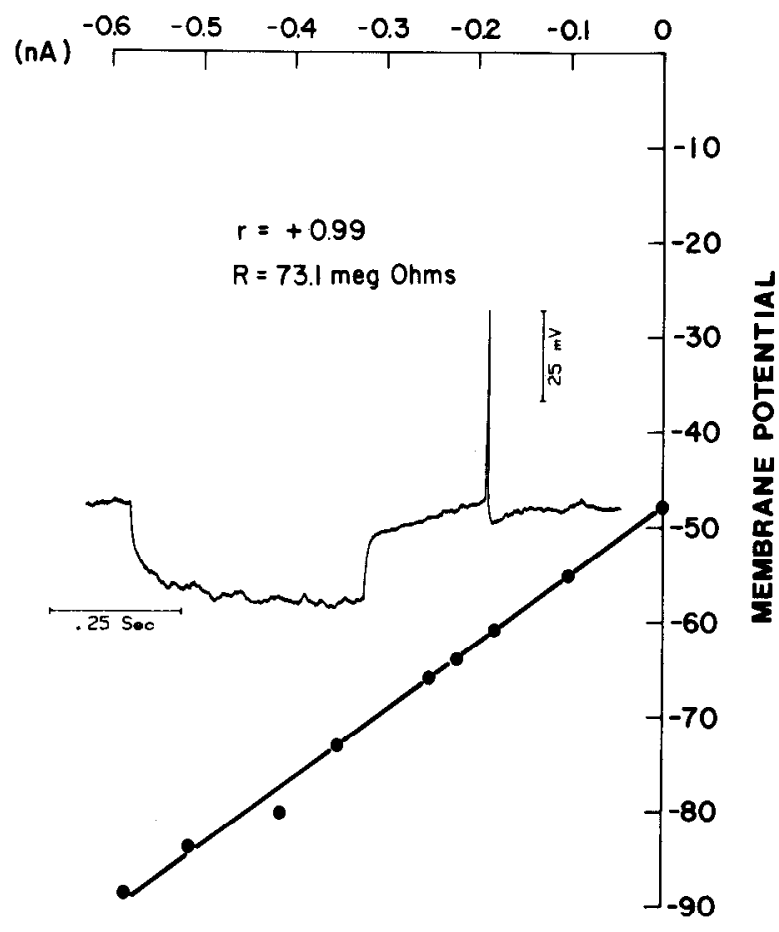

( $\mathrm{mV}$ )

Figure 14. DA cell input resistance following long-term (45 min or more) TEA injection. This is characterized by a marked increase in input resistance to values 2 to 3 times those observed in the control conditions. In addition, the TEA will block the anomalous rectification usually associated with large hyperpolarizations in DA neurons (a typical response is shown).

nally) initiate bursting, but inactivation of the $I_{\mathrm{K}(\mathrm{Ca})}$ by longer periods of TEA injection or by EGTA injection inhibit bursting; and (3) the action potential broadening accompanying burst firing, TEA injection, barium administration, and long-term depolarization has been associated with an inactivation of an $I_{\mathrm{K}(v)}$ in other preparations (Aldrich et al., 1979a, b; Gorman and Hermann, 1982; Gorman et al., 1982).

Bursts in DA cells appear to be repolarized by an $I_{\mathrm{K}(\mathrm{Ca})}$, as described for burst firing in the hippocampus (Alger and Nicoll, 1980; Hotson and Prince,1980; Schwartzkroin and Stafstrom, 1980; Hablitz, 1981a, b; Wong and Prince, 1981) and in a variety of invertebrate preparations (cf. Meech, 1978, 1979). However, it is not clear what event triggers this hyperpolarization which terminates the burst. One possibility may be that repolarization is dependent on the activation threshold of the $I_{\mathrm{K}(\mathrm{Ca})}$. Thus, in the hippocampus (Brown and Griffith, 1983a, b), in motoneurons (Barrett et al., 1980), and in sympathetic ganglia (Brown and Caulfield, 1979), the $I_{\mathrm{K}(\mathrm{Ca})}$ becomes activated at potentials positive to about $-45 \mathrm{mV}$. This current can therefore become activated in the short term by an action potential, and in the long term by a burst which attains a base line potential positive to $-45 \mathrm{mV}$, and in this way may contribute to terminating the burst event. In support of this mechanism of burst repolarization, Figures 1 and 11 show that the waves of depolarization upon which DA cell bursts are superimposed do not typically repolarize until 20 to 60 msec after the last spike in the bursts. It is therefore possible that DA cell bursts are terminated by an $I_{\mathrm{K}(\mathrm{Ca})}$ activated when the wave of depolarization upon which the burst is superimposed reaches the threshold for activation of the $I_{\mathrm{K}(\mathrm{Ca})}$.

Comparisons with other burst firing systems. Burst firing has

been described in a number of invertebrate and vertebrate preparations. Burst firing in DA neurons, while resembling burst firing characteristics exhibited in some invertebrate preparations, is nonetheless quite different from burst firing as described in other vertebrate brain regions. In the vertebrate, burst firing has been observed in the hippocampus (Kandel and Spencer, 1961; Schwartzkroin, 1977; Wong and Prince, 1978, 1981), cerebellum (Llinàs and Sugimori, 1980), thalamus (Deschênes et al., 1982; Llinàs and Jahnsen, 1982), dorsal column nucleus (Clarke's column; Calvin and Loeser, 1975), and the hypothalamus (Dreifuss et al., 1976; Vincent et al., 1978; Hatton, 1982). However, in all of these regions (with the exception of the hypothalamus), the burst time course is quite different from that observed in DA neurons. Thus, the above regions fire spikes in bursts with an interspike interval of 3 to $10 \mathrm{msec}$ (determined from burst examples presented in the above citations). This time course is sufficiently short to allow subsequent spikes in a burst to arise from the AHP rebound of the previous spike. Thus, at least one of the models proposed for burst firing in these regions fits well with the observed time course - the next spike is triggered by a rebound dendritic spike from the previously occurring action potential (Kandel and Spencer, 1961; Wong et al., 1979; Llinàs and Sugimori,1980; Llinàs and Jahnsen, 1982; Traub, 1982). In DA neurons, however, the average interspike interval in the burst is more than 70 msec; thus, a rebound dendritic spike would not be a plausible mechanism to account for burst firing. The second spike in a DA cell burst arises from a slow depolarization, with no dendritic spikes observed in the process. The only other area in the vertebrate CNS with bursts of a time course somewhat similar to that of DA cells was reported in the periventricular nucleus of the hypothalamus (Hatton, 1982), where an interspike interval of 30 to $40 \mathrm{msec}$ was reported.

Other differences have been noted between burst firing in DA neurons and bursting neurons observed in other brain regions. Thus, hyperpolarization will initiate bursting and depolarization will inhibit bursting in the hippocampus (Wong and Prince, 1981) and the thalamus (Llinàs and Jahnsen,1982) - responses which were opposite to those found in DA neurons. Furthermore, burst firing in other regions can be initiated by a short (e.g., $5 \mathrm{msec}$ ) depolarizing pulse (Kandel and Spencer, 1961; van Swigchem, 1979), whereas DA neurons require long periods of depolarization to initiate bursting and do not fire bursts in response to short (up to $50 \mathrm{msec}$ ) depolarizations. Lastly, bursting can be blocked by intracellular injection of EGTA in DA neurons, but EGTA administered to hippocampal pyramidal cells has been reported either to not affect bursting or to actually prolong the burst event (Alger and Nicoll, 1980; Hotson and Prince,1980; Hablitz, 1981a, b). In contrast, burst firing in neuron R15 of the invertebrate Aplysia can be completely suppressed by the intracellular administration of EGTA (Gorman and Hermann, 1982). Furthermore, both cell R15 and DA neurons require calcium to elicit bursts (Meech, 1974; Barker and Gainer, 1975a, b; Gorman and Hermann, 1982). However, too much external calcium will decrease bursting in cell R15 due to decreased excitability (Barker and Gainer, 1975b; Colmers et al., 1982), as shown here for DA neurons. Whether a similar mechanism for burst firing is in operation in both preparations has yet to be determined.

Burst-firing neurons have been described as having a number of charateristics in common. In Aplysia neuron R15 a large calcium current associated with the action potential, leading to a large amplitude $I_{\mathrm{K}(\mathrm{Ca})}$, was considered to be an important factor in the ability of this cell to fire in bursts (Gorman and Hermann, 1982). Others have suggested that a large calcium component of action potentials is involved in the ability of a neuron to fire in bursts. Thus, during burst firing the long calcium spike, by increasing the average level of depolarization 
during spiking, will lead to progressive inactivation of the $I_{\mathrm{K}(v)}$. This would result in further broadening of the action potential and thus in regeneratively inactivating this potassium current (Barker and Gainer, 1975a, b; Smith et al., 1975; Aldrich et al., $1979 a, b)$. Similar observations have been made here for burst firing in DA cells, suggesting that at least this mechanism underlying burst firing could possibly be a more widespread phenomenon.

Significance of burst firing. What role might burst firing play in DA system function? The nigrostriatal DA system appears to fire in two very different modes which are distinguished much more by specific firing patterns than by rate. When operating in the single spike mode, DA presynaptic autoreceptor stimulation might be expected to be diminished and tyrosine hydroxylase maximally active, increasing DA stores within terminals (Roth, 1979). A switch to a bursting mode would cause spikes to summate in the DA terminals of the striatum and result in a massive DA release. This would be followed immediately by a post-burst inhibition of DA ncuron firing, an inactivation of tyrosine hydroxylase by the combined influences of autoreceptor stimulation and calcium influx (Roth, 1979), and feedback inhibition of the DA neuron (Grace et al., 1980; Hommer and Bunney, 1980). When one considers that DA neurons project in individual groups to small, distinct terminal fields in the striatum (Swanson, 1982), that massive collateralization of DA axons must occur in the striatum within these small patches (Andèn et al., 1966), that synchronized DA cell discharge occurs as a result of electrical coupling between neighboring DA cells (Grace and Bunney, 1981, 1983c), and that single DA neurons have been seen to switch from an irregular firing pattern to a bursting mode in drug-free unrestrained animals (Meltzer and Bunney, 1984), a picture emerges of a small circumscribed group of DA neurons exerting massive control over a discrete region of the striatum in a pulsatile manner. Furthermore, if the excitation of the DA neuron is prolonged, the tendency of the cell to fire in bursts should be increased and should be accompanied by an activity-related increase in the rate of tyrosine hydroxylation, thus allowing for longer-term modulation of DA activity (Roth, 1979). Finally, with much longer periods of excitation, DA cells appear to go into a state of depolarization block and cease to fire action potentials altogether (Bunney and Grace, 1978; Chiodo and Bunney, 1983; White and Wang, 1983).

In summary, DA neurons appear to be capable of exhibiting four states: (1) spontaneously inactive due to hyperpolarization, (2) single spiking, (3) burst firing, and (4) drug-induced depolarization inactivation. When firing spontaneously, DA cells typically fire in a single spike mode with rapid accommodation to short depolarizing pulses. However, in response to an increased demand, the DA neurons can switch to a burst firing mode and thus more effectively generate spikes in response to an excitatory influence. Furthermore, external manipulations, such as chronic antipsychotic drug treatment, or CCK (Skirboll et al., 1981) or glutamate iontophoresis, can increase the demand on the DA system sufficiently to drive the DA cells into depolarization block (Bunney and Grace, 1978).The inability of investigators to find reliable evidence of DA modulation of striatal neuron firing in response to nigral stimulation may be related to the pattern of stimulation used. Thus, if short bursts of stimulating current were used rather than just single pulses, one might be able to observe more reliably a specific DA action on postsynaptic cells due to the hypothesized markedly increased release of dopamine. Preliminary evidence suggests that this is the case (J. O. Schenk and B. S. Bunney, manuscript in preparation).

\section{References}

Adams, D. J., and P. W. Gage (1980) Divalent ion currents and delayed potassium conductance in an Aplysia neurone. J. Physiol. (Lond.)
304: $297-313$

Adams, P. R., A. Constanti, D. A. Brown, and R. B. Clark (1982) Intracellular $\mathrm{Ca}^{+}$activates a fast voltage-sensitive $\mathrm{K}^{+}$current in vertebrate sympathetic neurons. Nature 296: 746-749.

Aghajanian, G. K., and B. S. Bunney (1977) Dopamine "autoreceptors": Pharmacological characterization by microiontophoretic single unit recording studies. Naunyn Schmiedeberg's $\Lambda$ rch. Pharmacol. 297: 1-

Akaike, N., A. M. Brown, G. Dahl, H. Higashi, G. Isenborg, Y. Tsuda, and A. Yatani (1983) Voltage-dependent activation of potassium current in Helix neurons by endogenous calcium. J. Physiol. (Lond.) 334: 309-324.

Aldrich, R. W., P. A. Getting, and S. H. Thompson (1979a) Inactivation of delayed outward current in molluscan neurone somata. J. Physiol. (Lond.) 291: 507-530.

Aldrich, R. W., P. A. Getting, and S. H. Thompson (1979b) Mechanism of frequency-dependent broadening of molluscan neurone soma spikes. J. Physiol. (Lond.) 291: 531-544.

Alger, B. E., and R. A. Nicoll (1980) Epileptiform burst after-hyperpolarization: Calcium-dependent potassium potential in hippocampal CA1 pyramidal cells. Science 210:1122-1121.

Andèn, N. -E., K. Fuxe, B. Hamberger, and T. Hökfelt (1966) A quantitative study of the nigro-neostriatal dopamine neuron system in the rat. Acta Physiol. Scand. 67: 306-312.

Armstrong, C. M., and S. R. Taylor (1980) Interaction of barium ions with potassium channels in squid giant axons. Biophys. J. 30:473488.

Barker, J. L., and H. Gainer (1975a) Studies on bursting pacemaker potential activity in molluscan neurons. I. Membrane properties and ionic contributions. Brain Res. 84: 461-477.

Barker, J. L., and H. Gainer (1975b) Studies on bursting pacemaker potential activity in molluscan neurons. II. Regulation by divalent cations. Brain Res., 84: 479-500.

Barrett, E. F., J. N. Barrett, and W. E. Crill (1980) Voltage-sensitive outward currents in cat motoneurons. J. Physiol. (Lond.) 304: 251276.

Benjamin, P. R. (1978) Endogenous and synaptic factors affecting the bursting of double spiking molluscan neurosecretory neurons. In Abnormal Neuronal Discharges, N. Chalazonitis and M. Boisson, eds., pp. 205-216, Raven Press, New York.

Benjamin, P. R., and N. U. Swindale (1975) Electrical properties of "dark green" and "yellow" neurosecretory cells in the snail Lymnaea stagnalis L. Nature 258: 622-623.

Blaustein, N. P., and D. E. Goldman (1966) Competitive action of calcium and procaine on lobster axon. J. Gen. Physiol. 49: 10431063

Blaustein, N. P., and M. T. Nelson (1982) Sodium-calcium exchange: Its role in the regulation of cell calcium. In Calcium Transport across Biological Membranes, E. Caratoli, ed., pp. 217-236, Academic Press, Inc., New York.

Bloom, F. E. (1974) To spritz or not to spritz: The doubtful value of aimless iontophoresis. Life Sci. 14: 1819-1834.

Bloom, F. E. (1975) Amine receptors in CNS. I. Norepinephrine. In Handbook of Psychopharmacology, L. L. Iversen, S. D. Iversen, and S. H. Snyder, eds., Vol. 6, pp. 1-22, Raven Press, New York.

Borle, A. B. (1982) Control, modulation and regulation of cell calcium. Rev. Physiol. Biochem. Pharmacol. 90: 13-153.

Brink, F. (1954) The role of calcium ions in neural processes. Pharmacol. Rev. 6: 243-298.

Brown, D. A., and M. P. Caulfield (1979) Hyperpolarizing "alpha-2"adrenoceptors in rat sympathetic ganglia. Br. J. Pharmacol. 65: 435 445

Brown, D. A., and W. H. Griffith (1983a) Calcium-activated outward current in voltage-clamped hippocampal neurones of the guinea pig. J. Physiol. (Lond.) 337: 287-301.

Brown, D. A., and W. H. Griffith (1983b) Persistent slow inward calcium current in voltage-clamped hippocampal neurones of the guinea-pig. J. Physiol. (Lond.) 337: 303-320.

Bumney, B. S., and A. A. Grace (1978) Acute and chronic haloperidol treatment: Comparison of effects on nigral dopaminergic cell activity. Life. Sci. 23: 1715-1728.

Bunney, B. S., J. R. Walters, R. H. Roth, and G. K. Aghajanian (1973) Dopaminergic neurons: Effect of antipsychotic drugs and amphetamine on single cell activity. J. Pharmacol. Exp. Ther. 185: 560-571.

Calvin, W. H. (1974) Three modes of repetitive firing and the role of threshold time course between spikes. Brain Res. 69: 341-346.

Calvin, W. H., and J. D. Loeser (1975) Doublet and burst firing patterns 
within the dorsal column nuclei of cat and man. Exp. Neurol. 48: 406-426.

Carafoli, E., and M. Crompton (1978) The regulation of intracellular calcium. Curr. Top. Membr. Transp. 10: 151-216.

Chiodo, L. A., and B. S. Bunney (1983) Typical and atypical neuroleptics: Differential effects of chronic administration on the activity of A9 and A10 midbrain dopaminergic neurons. J. Neurosci. 3: 16071619.

Colmers, W. F., D. V. Lewis, and W. A. Wilson (1982) $\mathrm{Ca}^{+}$loading reveals $\mathrm{Na}^{+}$-dependent persistent inward current and negative slope resistance region in Aplysia giant neurons. J. Neurophysiol. 48: 11911200 .

Connor, J. A. (1977) Time course separation of two inward currents in molluscan neurons. Brain Res. 119: 487-492.

Deschênes, M., J. P. Roy, and M. Steriade (1982) Thalamic bursting mechanism: An inward slow current revealed by membrane hyperpolarization. Brain Res. 239: 289-293.

Domesick, V. B. (1979) Cytology of dopamine and nondopamine cells of the substantia nigra in the rat: A light- and electron-microscopic study. Anat. Rec. 193: 525-526.

Domesick, V. B. (1981) The anatonical basis for feedback and feedforward in the striatonigral system. In Apomorphine and Uther Dopaminomimetics. Basic Pharmacology, G. L. Gessa and G. V. Corsini, eds., pp. 27-39, Raven Press, New York.

Dreifuss, J. J., E. Tribollet, and A. J. Baertschi (1976) Excitation of S. $O$. neurons by vaginal distention in lactating rats: Correlation with neurohypophysial hormone release. Brain Res. 11:3: 600-605.

Dreifuss, J. J., B. H. Gähwiler, and P. Sandoz (1978) Burst firing in a mammalian endocrine neuron. In Abnormal Neuronal Discharges, Eds. N. Chalazonitis and M. Boisson, eds., pp. 111-114, Raven Press, New York.

Eaton, D. C., and M. S. Brodwick (1978) Barium block of potassium currents. Biophys. J. 21: 164a.

Eaton, D. C., and M. S. Brodwick (1980) Effects of barium on the potassium conductance of squid axon. J. Gen. Physiol. 75: 727-750.

Eckert, R., and H. D. Lux (1976) A voltage-sensitive persistent calcium conductance in neuronal somata of Helix. J. Physiol. (Lond.) 254: $129-151$.

Endo, M. (1977) Calcium release from the sarcoplasmic reticulum. Physiol. Rev. 57: 71-108.

Feldman, S. C., and S. Christakos (1983) Vitamin D-dependent calcium-binding protein in rat brain: Biochemical and immunocytochemical characterization. Endocrinology 112: 290-302.

Fiskum, G., and A. L. Lehninger (1982) Mitochondrial regulation of intracellular calcium. In Calcium and Cell Function, W. Y. Cheung, ed., pp. 39-80, Academic Press, Inc., New York.

Frankenhauser, B., and A. L. Hodgkin (1957) The action of calcium on the electrical properties of squid axons. J. Physiol. (Lond.) 137: 218244.

Gainer, H. (1972a) Patterns of protein synthesis in individual, identified molluscan neurons. Brain Res. 39: 369-385.

Gainer, H. (1972b) Effects of experimentally induced diapause on the electrophysiology and protein synthesis patterns of identified molluscan neurons. Brain Res 39: 387-402.

Gainer, H. (1972c) Electrophysiological behavior of an endogenously active neurosecretory cell. Brain Res. 39: 403-418.

Gillary, H. L., and D. Kennedy (1969a) Pattern generation in a crustacean motoneuron. J. Neurophysiol. 32: 595-606.

Gillary, H. L., and D. Kennedy (1969b) Neurotransmitter effects of impulse pattern in a crustacean motoneuron. J. Neurophysiol. 32: 607-612.

Gola, M., C. Ducreaux, and H. Chagneux (1977) Ionic mechanism of slow potential wave production in barium-treated Aplysia neurons. J. Physiol. (Paris) 73: 407-440.

Gorman, A. L. F., and A. Herman (1979) Internal effects of divalent cations on potassium permeability in molluscan neurons. J. Physiol. (Lond.) 296: 393-410.

Gorman, A. L. F., and A. Hermann (1982) Quantitative differences in the currents of bursting and beating molluscan pace-maker neurons. J. Physiol. (Lond.) 333: 681-699.

Gorman, A. L. F, and M. V. Thomas (1980) Potassium conductance and internal calcium accumulation in a molluscan neuron. I. Physiol. (Lond.) 308: 287-313.

Gorman, A. L. F., A. Hermann, and M. V. Thomas (1982) Ionic requirements for membrane oscillations and their dependence on the calcium concentration in a molluscan pace-maker neurone. J. Physiol. (Lond.) 327: 185-217.
Grace, A. A., and B. S. Bunney (1981) Possible electrotonic coupling between sets of rat nigral dopaminergic neurons. Soc. Neurosci. Abstr. 7: 573

Grace, A. A., and B. S. Bunney (1983a) Intracellular and extracellular electrophysiology of nigral dopaminergic neurons. I. Identification and characterization. Neuroscience 10:301-315.

Grace, A. A., and B. S. Bunney (1983b) Intracellular and extracellular electrophysiology of nigral dopaminergic neurons. II. Action potential generating mechanisms and morphological correlates. Neuroscience 10: $317-331$.

Grace, A. A., and B. S. Bunney (1983c) Intracellular and extracellular electrophysiology of nigral dopaminergic neurons. III. Evidence for electrical coupling. Neuroscience 10:333-348.

Grace, A. A., and B. S. Bunney (1983d) Single spiking and burst firing in nigral dopamine neurons. Soc. Neurosci. Abstr. 9: 1006.

Grace, A. A., and B. S. Bunney (1984) The control of firing pattern in nigral dopamine neurons: Single spike firing. J. Neurosci. 4: 28662876.

Grace, A. A., D. W. Hommer, and B. S. Bunney (1980) Peripheral and striatal influences on nigral dopamine cells: Mediation by reticulata neurons. Brain Res. Bull. 5 (Suppl. 2): 105-109.

Groves, P. M., and J. C. Linder (1983) Dendro-dendritic synapses in substantia nigra: Descriptions based on analysis of serial sections. Exp. Brain Res. 49: 209-217.

Gulley, R. L., and R. L. Wood (1971) The fine structure of the neurons in the rat substantia nigra. Tissue Cell 3: 675-690.

Hablitz, J. J. (1981a) Altered burst responses in hippocampal CA3 neurons injected with EGTA. Exp. Brain Res. 42: 483-485.

Hablitz, J. J. (1981b) Effects of intracellular injections of chloride and EGTA on postepileptiform burst-hyperpolarizations in hippocampal neurons. Neurosci. Lett. 22: 159-163.

Hablitz, J. J., and D. Johnston (1981) Endogenous nature of spontaneous bursting in hippocampal pyramidal neurons. Cell. Mol. Neurobiol. 1: $325-334$.

Hagiwara, S., J. Fukuda, and D. C. Eaton (1974) Membrane currents carried by $\mathrm{Ca}, \mathrm{Sr}$ and $\mathrm{Ba}$ in barnacle muscle fiber during voltage clamp. J. Gen. Physiol. 63: 564-578.

Hahin, R., and D. T. Campbell (1983) Simple shifts in the voltage dependence of sodium channel gating caused by divalent cations. J. Gen. Physiol. 82: 785-805.

Hatton, G. I. (1982) Phasic bursting activity of rat paraventricular neurones in the absence of synaptic transmission. J. Physiol. (Lond.) 327: $273-284$.

Hattori, T., P. L. McGeer, and E. G. McGeer (1979) Dendro-axonic neurotransmission. II. Morphological sites for the synthesis, binding and release of neurotransmitters in dopaminergic dendrites in the substantia nigra and cholinergic dendrites in the neostriatum. Brain Res. 170: 71-83.

Hayward, J. N., and D. P. Jennings (1973) Activity of magnocellular neuroendocrine cells in the hypothalamus of unanaesthetized monkeys. I. Functional cell types and their anatomical distribution in the supraoptic nucleus and the internuclear zone. J. Physiol. (Lond.) 232: $515-543$.

Henkart, M. P., and P. G. Nelson (1979) Evidence for an intracellular calcium store releasable by surface stimuli in fibroblasts ( $\mathrm{L}$ cells). $\mathrm{J}$. Physiol. (Lond.) 73: 655-673.

Henkart, M. P., D. Landis, and T. S. Reese (1976) Similarity of junctions between plasma membranes and endoplasmic reticulum in muscle and neurons. J. Cell Biol. 70: 338-347.

Henke, H., P. H. Tobler, and J. A. Fischer (1983) Localization of salmon calcitonin binding sites in rat brain by autoradiography. Brain Res. 272: 373-377.

Hermann, A., and A. L. F. Gorman (1979) Blockade of voltage-dependent and $\mathrm{Ca}^{2+}$-dependent $\mathrm{K}^{+}$current by internal $\mathrm{Ba}^{2+}$ in molluscan pacemaker neurons. Experientia 35: 229-231.

Hillman, H. H., and H. McIlwain (1961) Membrane potentials in mammalian cerebral tissues in vitro: Dependence on ionic environment. J. Physiol. (Lond.) 157: 263-278.

Hofmeier, G., and H. D. Lux (1981) The time course of intracellular free calcium and related electrical effects after injection of $\mathrm{CaCl}_{2}$ into neurons of the snail, Helix pomatia. Pflügers Archiv. 391: 242251.

Hökfelt, T., and U. Ungerstedt (1973) Specificity of 6-hydroxydopamine-induced degeneration of central monoamine neurons: An elec tron and fluorescence-microscopic study with special reference to intracerebral injection on the nigrostriatal system. Brain Res. 60 : 269-297. 
Hommer, D. W., and B. S. Bunney (1980) Effect of sensory stimuli on the activity of dopaminergic neurons: Involvement of non-dopaminergic nigral neurons and striato-nigral pathways. Life Sci. 27: 377386.

Hotson, J. R., and D.A. Prince (1980) A calcium-activated hyperpolarization follows repetitive firing in hippocampal neurons. J. Neurophysiol. 43: 409419.

Hotson, J. R., and D. A. Prince (1981) Penicillin- and barium-induced epileptiform bursting in hippocampal neurons. Ann. Neurol. 10: 1117.

Johnston, D., J. J. Hablitz, and W. A. Wilson (1980) Voltage clamp discloses slow inward current in hippocampal burst-firing neurones. Nature 286: 391-393.

Kandel, E. R., and W. A. Spencer (1961) Electrophysiology of hippocampal neurons. II. After-potentials and repetitive firing. J. Neurophysiol. 24: 243-259.

Kato, G., and G. Somjen (1969) Effects of microiontophoretic administration of magnesium and calcium on neurones in the central nervous system. J. Neurobiol. 2: 181-195.

Kelley, J. S., K. Krnjèvic, and G. Somjen (1969) Divalent cations and electrical properties of cortical cells. J. Neurobiol. 2: 197-208.

Kostyuk, P. G., and O. A. Krishtal (1977) Effects of calcium and calcium-chelating agents on the inward and outward current in the membrane of mollusc neurones. J. Physiol. (Lond.) 270: 569-580.

Krnjevik, K. (1965) Actions of drugs on single neurones in the cerebral cortex. Br. Med. Bull. 21: 10-14.

Lehninger, A. L. (1970) Mitochondrial and calcium ion transport. Biochem. J. 119: 129-138.

Lewis, D. V., and W. A. Wilson (1982) Calcium influx and poststimulus current during early adaptation in Aplysia giant neurons. J. Neurophysiol. 48: 202-216.

Lincoln, D. W., and J. B. Wakerly (1974) Electrophysiological evidence for the activation of supraoptic neurons during the release of oxytocin. J. Physiol. (Lond.) 242: 533-554.

Linder, J. C., S. J. Young, and P. M. Groves (1982) Dendro-dendritic synapses in substantia nigra: Quantitative descriptions based on serial electron micrographs. Soc. Neurosci. Abstr. 8: 169.

Llinàs, R., and H. Jahnsen (1982) Electrophysiology of mammalian thalamic neurones in vitro. Nature 297: 406-408.

Llinàs, R., and M. Sugimori (1980) Electrophysiological properties of in vitro Purkinje cell dendrites in mammalian cerebellar slices. J. Physiol. (Lond.) 305: 197-213.

Lux, HI. D., and G. Hofmeier (1982) Properties of a calcium- and voltage-activated potassium current in Helix pomatia neuron. Pflügers Arch. 394: 61-69.

Magura, I. S. (1977) Long-lasting inward current in snail neurons in barium solutions in voltage-clamp conditions. J. Membr. Biol. 35: 239-256.

McAfee, D. A., and P. J. Yarowsky (1979) Calcium-dependent potentials in the mammalian sympathetic neurone. J. Physiol. (Lond.) 290: $507-523$.

Meech, R. W. (1974) Prolonged action potentials in Aplysia neurones injected with EGTA. Comp. Biochem. Physiol. 48A: 397-402.

Meech, R. W. (1978) Calcium-dependent potassium activation in nervous tissues. Annu. Rev. Biophys. Bioeng. 7: 1-18.

Meech, R. W. (1979) Membrane potential oscillations in molluscan "burster" neurones. J. Exp. Biol. 81: 93-112.

Meltzer, L. T., and B. S. Bunney (1984) Nigral dopaminergic neurons: Single unit activity in the awake, unrestrained rat. Life Sci., in press.

Mercer, L., M. del Fiacco, and A. C. Cuello (1979) The smooth endoplasmic reticulum as a possible storage site for dendritic dopamine in substantia nigra neurones. Fxperientia 35: 101-103.

Olgiati, V. R., F. Guidobono, C. Netti, and A. Pecile (1983) Localization of calcitonin binding sites in rat central nervous system: Evidence of its neuroactivity. Brain Res. 265: 209-215.

Rinvik, E., and I. Grofovà (1970) Observations on the fine structure of the substantia nigra in the cat. Exp. Brain Res. 11: 229-248.

Rosenbluth, J. (1962) Subsurface cisterns and their relationship to the neuronal plasma membrane. J. Cell Biol. 13: 405-421.

Roth, R. H. (1979) Dopamine autoreceptors: Pharmacology, function and comparison with post-synaptic dopamine receptors. Commun. Psychopharmacol. 3: 429-445.

Schwartzkroin, P. A. (1977) Further characteristics of hippocampal CA1 cells in vitro. Brain Res. 128: 53-68.

Schwartzkroin, P. A., and C. E. Stafstrom (1980) Effects of EGTA on the calcium-activated afterhyperpolarization on hippocampal CA3 pyramidal cells. Science $210: 1125-1126$

Skirboll, L. R., A. A. Grace, D. W. Hommer, J. Rehfeld, M. Goldstein, T. Hökfelt, and B. S. Bunney (1981) Peptide-monoamine coexistence: Studies of the actions of cholecystokinin-like peptide on the electrical activity of midbrain dopamine neurons, Neuroscience 6 : $2111-2124$

Smith, T. G., J. L. Barker, and H. Gainer (1975) Requirements for bursting pacemaker potential activity in molluscan neurones. Nature 253: $450-452$.

Sotelo, C. (1971) The fine structural localization of norepinephrine- ${ }^{3} \mathrm{H}$ in the substantia nigra and area postrema of the rat. An autoradiographic study. J. Ultrastruct. Res. 36: 824-841.

Sotelo, C., and D. Riche (1975) Ultrastructural identification of nigral dopaminergic cells in the rat. Exerpta Med. Int. Congr. Ser. 359: $425-431$.

Stanfield, P. R., and N. B. Standen (1978) A potential and time dependent blockade of inward rectification in frog skeletal muscle fibers by $\mathrm{Ba}^{++}$and $\mathrm{Sr}^{++}$. J. Physiol. (Lond.) 280: 169-192.

Stinus, L., P. A. Paskevich, and V. D. Domesick (1981) Morphological identification of dopaminergic neurons in the rat substantia nigra and ventral tegmental area. Anat. Rec. 199: 246A.

Sugaya, E., and M. Onozuka (1978a) Intracellular calcium: its movement during pentylenetetrazole-induced bursting activity. Science 200: 797-799.

Sugaya, E., and M. Onozuka (1978b) Intracellular calcium: Its release from granules during bursting activity in snail neurones. Science 202: $1195-1197$.

Sugaya, E., and M. Onozuka (1978c) Ion shower milling: Its application to cell membrane removal. Science 202: 1197-1198.

Sugaya, E., M. Onozuka, M. Usami, and A. Sugaya (1978) Ionic distribution changes during bursting activity induced by pentylenetetrazol in a single isolated snail neuron: Tentative application of electron probe X-ray microanalyzer to a single isolated neuron. In Abnormal Neuronal Discharges, N. Chalazonitis and M. Boisson, eds., pp. 407-418, Raven Press, New York.

Sugaya, E., M. Onozuka, H. Furuichi, and A. Sugaya (1981a) Cellular calcium binding state change during pentylene tetrazol induced bursting activity in snail neurons. Experientia 37: 1080-1081.

Sugaya, E., M. Onozuka, H. Furuichi, and A. Sugaya (1981b) Intramembranous particle charge during pentylene tretrazol induced bursting activity in snail neurons. Experientia 37: 1081-1082.

Sugaya, E., M. Onozuka, K. Kishi, A. Sugaya, and T. Tsuda (1982) Intracellular protein changes during pentylenetetrazol induced bursting activity in snail neurons. Brain Res. 253: 271-279.

Swanson, L. W. (1982) The projection of the ventral tegmental area and adjacent regions: $A$ combined fluorescent retrograde tracer and immunofluorescence study in the rat. Brain Res. Bull. 9: 321-353.

Traub, R. D. (1982) Simulation of intrinsic bursting in CA3 hippocampal neurons. Neuroscience 7: 1233-1242.

van Swigchem, H. (1979) On the endogeneous bursting properties of "light yellow" neurosecretory cells in the freshwater snail Lymnea stagnalis (L.). J. Exp. Biol. 80: 55-67.

Vincent, J. D., D. A. Poulain, and E. Arnaud (1978) Bursting activity in relation to neurosecretory processes in hypothalamic neurosecretory cells. In Abnormal Neuronal Discharges, N. Chalazonitis and M. Boisson, eds., pp. 103-110, Raven Press, New York.

Wassef, M., A. Berod, and C. Sotelo (1981) Dopaminergic dendrites in the pars reticulata of the rat substantia nigra and their striatal input. Combined immunocytochemical localization of tyrosine hydroxylase and anterograde degeneration. Neuroscience 6:2125-2139.

White, F. J., and R. Y. Wang (1983) Comparison of the effects of chronic haloperidol treatment on $\mathrm{A} 9$ and $\mathrm{A} 10$ dopamine neurons in the rat. Life Sci. 32: 983-993.

Wong, R. K. S., and D. A. Prince (1978) Participation of calcium spikes during intrinsic burst firing in hippocampal ncurons. Brain Res. 159 385-390.

Wong, R. K. S., and D. A. Prince (1981) Afterpotential generation in hippocampal pyramidal cells. J. Neurophysiol. 45: 86-97.

Wong, R. K. S., D. A. Prince, and A. I. Busbaum (1979) Intradendritic recordings from hippocampal neurons. Proc. Natl. Acad. Sci. U. S. A. $76: 986-990$.

Wood, J., B. Rosario, and P. Owens (1983) X-ray microanalysis of dopamine storage sites in primate substantia nigra neurons. Soc. Neurosci. Abstr. 9: 1151.

Woolum, J. C., and A. L. F. Gorman (1981) Time dependence of the calcium-activated potassium current. Biophys. J. 36: 297-302. 